\title{
El presupuesto de culto en la Argentina del siglo xIX. Debates historiográficos y un estudio de caso: Tucumán, 1861-1897*
}

\author{
The Budget for Worship in Argentina in \\ the 19th Century. Historiographic Debates \\ and a Case Study: Tucumán, 1861-1897
}

\author{
Esteban Ábalo** \\ (1) https://orcid.org/0000-0002-3559-0026 \\ Universidad del Norte Santo Tomás de Aquino, Tucumán, Argentina \\ abaloe@gmail.com
}

Resumen: La asignación de fondos por parte del Estado para financiar el culto católico en Argentina ha sido y es un tema de discusión tanto en el ámbito académico como fuera de él. El significado de esos aportes, su pertinencia, su origen histórico, son algunas de las cuestiones que se han discutido durante gran parte del siglo xx y los años que corren del actual. En el presente artículo se propone hacer una revisión de algunas de las conclusiones a las cuales

* La investigación inicia en 1861, año de la realización de los primeros aportes que registra la fuente consultada para el culto católico y se detiene en 1897, año de la elevación de Tucumán a sede episcopal. Hasta ese momento la provincia era, en lo eclesiástico, una vicaría foránea dependiente del obispado de Salta.

** Deseo agradecer a los evaluadores anónimos que realizaron una generosa lectura y aportaron valiosas sugerencias para este trabajo.

cómo citaR: Ábalo, E. (2020). El presupuesto de culto en la Argentina en el siglo xix. Debates historiográficos y un estudio de caso: Tucumán, 1861-1897. Secuencia (107), e1548. DoI: https://doi.org/10.18234/ secuencia.v0i107.1548 
llegaron investigaciones precedentes, tanto en el pasado más o menos remoto, como en la actualidad. Por último, se pretende poner a discusión esas conclusiones con el estudio de un caso particular: el presupuesto estatal de culto en la provincia de Tucumán durante las últimas cuatro décadas del siglo XIX.

Palabras clave: presupuesto de culto; Argentina; siglo xIx; Tucumán; Iglesia católica.

Abstract: The allocation of funds by the state to finance Catholic worship in Argentina has been and remains a topic of discussion both inside and outside academia. The meaning of these contributions, their relevance and historical origin, are some of the issues that have been discussed during much of the 20th century and the present. This article seeks to survey some of the conclusions reached by previous research, in both the distant past and today. Finally, the aim is to compare these conclusions with a case study: the state budget for worship in the province of Tucumán during the last four decades of the 19th century.

Keywords: budget for worship; Argentina; 19th century; Tucumán; catholic Church.

Recibido: 23 de agosto de 2017 Aceptado: 11 de marzo de 2019

Publicado: 13 de febrero de 2020

\section{INTRODUCCIÓN}

$E_{c}^{1}$ sustento por parte del Estado de algunos aspectos relacionados con el culto católico es un tema de debate historiográfico que comenzó a hacerse presente a mediados del siglo xx, recuperando algo de esa relevancia en el contexto de la renovación de los estudios sobre la historia de la Iglesia en Argentina durante las últimas décadas del mismo siglo y las primeras del corriente.

El problema del "desvío" o no de fondos del erario público para el culto se inscribió a su vez en un debate mayor sobre la naturaleza de las relaciones establecidas entre Iglesia y Estado en Argentina, y sirvió en parte para abonar la hipótesis del enfrentamiento entre ambas instituciones, utilizando 
los orígenes del aporte estatal y los montos de dichos presupuestos como un argumento para tildar de irreligiosos o proclericales a los distintos gobiernos según sus aportes hayan sido más generosos o más escasos. De esta forma, problemas como la expropiación de bienes y la "justa retribución” a la Iglesia vinieron a opacar los análisis con juicios de valor sobre el comportamiento más o menos adecuado, más o menos liberal o más o menos católico de los gobernantes en turno (Gallardo, 1962; Rottjër, 1958; Udaondo, 1957).

En el mencionado contexto de la renovación de la historiografía de la Iglesia católica de las últimas décadas, ${ }^{1}$ otros autores han profundizado en esta cuestión intentando vislumbrar a través del problema del presupuesto de culto la relación entre liberalismo decimonónico y catolicismo, y también comprender mejor la polimorfa constitución de esos colectivos que a veces funcionan como abstracciones distorsionantes.

Una relectura de esas propuestas historiográficas es complementada aquí con el aporte de nuevos datos provenientes de un estudio de caso que tiene como eje el presupuesto de culto en la provincia de Tucumán durante la segunda mitad del siglo xIX. La intención que persigue la inclusión de este es la de analizar cómo se desarrolló en una provincia en particular la puesta en funcionamiento de un presupuesto de culto. Cómo estaba compuesto el mismo, cuáles eran los ítems que incluía, qué aspectos del culto cubría, y cómo evolucionó durante casi 40 años, son algunas de las cuestiones que pueden percibirse a partir de este estudio.

Utilizando este caso, se propone acceder al análisis de algunas cuestiones como las formas y el sentido de la cooperación económica del Estado para con la Iglesia, el derrotero del proceso de laicización en la provincia, y las pretensiones patronales de los gobiernos en turno.

${ }^{1}$ Esta renovación estuvo encabezada, a partir de la década de 1980, por investigadores como Carlos Mayo, Susana Bianchi, Roberto Di Stefano, Valentina Ayrolo, Miranda Lida, Jaime Peire, María Elena Barral, Lila Caimari, Loris Zanatta, Ignacio Martínez, Diego Mauro, José Zanca, entre otros. Sobre los alcances, las temáticas y los aportes de esta nueva producción historiográfica, véase Lida (2007b). 


\section{EL ORIGEN DEL PRESUPUESTO DE CULTO EN BUENOS AIRES. LAS REFORMAS RIVADAVIANAS ${ }^{2}$}

\section{El reemplazo del sistema de diezmos por un presupuesto de culto en Buenos} Aires mediante la ley de Reforma del Clero de 1822 en el marco de las denominadas reformas rivadavianas, fue durante mucho tiempo un eje de conflicto para polemistas que tenían como objetivo defender o atacar la existencia de dicho aporte. Los primeros estudios sobre este tema se concentran en intentar demostrar la "justicia" del aporte estatal a la Iglesia y trazar una genealogía de sus orígenes. Enrique Udaondo (1957), en la advertencia a la segunda edición de su libro Antecedentes del presupuesto de culto en la República Argentina del año 1957,3 afirma que la aparición de esta nueva edición se debía a la ignorancia generalizada sobre "la justicia de este precepto legal del sostenimiento del culto por el Estado Argentino”. En la misma línea, en la primera página del primer capítulo, el autor vuelve a afirmar que existe un error entre algunos sectores que por desconocimiento creen que el presupuesto de culto contiene "asignaciones contrarias a los principios de la economía y justicia que deben presidir la distribución de las rentas públicas” (Udaondo, 1957, p. 9). Por su parte, en la misma coyuntura de la amenaza de supresión del presupuesto de culto, la Comisión de Documentación y Publicidad del Episcopado argentino

${ }^{2}$ El proceso llamado "reformas rivadavianas", también conocido como "feliz experiencia porteña", hace referencia a una serie de modificaciones que se hicieron extensivas tanto a aspectos sociales como políticos y económicos durante el gobierno de Martín Rodríguez (1820-1824) en la provincia de Buenos Aires e impulsadas principalmente por su ministro de gobierno, Bernardino Rivadavia. Las mismas tenían como objetivo la modernización del aparato institucional heredado de la colonia en el contexto de crisis política abierto con la caída del gobierno central. En el aspecto religioso, dicha reforma representó, según Nancy Calvo (2001), una continuidad con la política religiosa llevada adelante por la monarquía española durante la segunda mitad del siglo xviII. Considera la autora que "como parte de un plan más general que involucra al Estado provincial en formación y a la sociedad en su conjunto, la reforma de la Iglesia se propone contribuir a la 'modernización' política y económica de la provincia. Así, la ley de reforma extiende la igualdad jurídica y procura uniformar al clero y 'nacionalizar' su formación, contribuyendo, de este modo, a la construcción de la declamada ciudadanía. Al mismo tiempo, pretende facilitar las condiciones de la expansión ganadera mejorando la distribución de las parroquias rurales, suprimiendo los diezmos y promoviendo la condición de 'agente estatal' civilizador de los párrocos de campaña" (p. 74). Otras obras que dan cuenta del proceso y que son de consulta imprescindible: Frizzi de Longoni (1947), Gallardo (1962), Piccirilli (1943). Para una perspectiva más actualizada, véase Di Stefano (2008).

3 Tanto en la edición 1949 como en 1956 se discutieron y llevaron a cabo modificaciones a la Constitución Nacional Argentina. 
encargó a Anibal Röttjer la elaboración de un documento sobre el tema en cuya introducción, a cargo del arzobispo de La Plata, José Antonio Plaza, se lee que su objetivo es el de demostrar "la incompetencia de la autoridad civil para suprimir por propia iniciativa el exiguo monto que constituye el presente presupuesto" (Rötjjer, 1958). En su argumentación, Rötjjer pretende, como Udaondo, demostrar la justicia de este emolumento del erario público en términos de reparación histórica por las repetidas expropiaciones realizadas por los gobiernos del siglo xix de rentas y propiedades de la Iglesia.

La enumeración de Röttjer sobre los atropellos cometidos por los diferentes gobiernos contra los bienes de la institución da inicio con la abolición de los diezmos en Buenos Aires en el contexto de las reformas rivadavianas, que se completó con la "apropiación" de los bienes eclesiásticos, en referencia a las propiedades e inmuebles de los monasterios que habían sido suprimidos por no contar con un número suficiente de residentes. A estos bienes se suman una serie de incautaciones en las provincias durante la primera mitad del siglo xix. En el libro se incluyen datos de La Rioja, Corrientes, San Luis, Tucumán, Santiago del Estero, Mendoza, Córdoba, Salta y Jujuy. Por lo tanto, para Rötjjer (1958), la conservación del presupuesto de culto no sólo correspondía por derecho, sino que los montos a los cuales se elevaba no llegaban a compensar "el latrocinio cometido" contra la institución (p. 39).

Para Udaondo (1957), por su parte, el carácter de retribución también está en el centro de la cuestión. Según el autor, la contribución del Estado al sostenimiento del culto católico no está sólo fundada en "altas razones históricas", sino que "no es más que una reintegración, en mínima proporción, de los bienes de la Iglesia que pasaron al Estado". Al argumentar sobre este particular, el autor remite también al contexto de la feliz experiencia porteña cuando "el Estado se incautó y despojó violentamente a la Iglesia de multitud de propiedades y establecimientos que le pertenecían”, privando a la institución de una fuente de recursos. Este embargo es el que obliga al Estado, "en moral y en justicia”, a subvencionarla e indemnizarla (Udaondo, 1957, p. 15). A su vez, esta expropiación ilegítima de los bienes de la Iglesia por parte del Estado es la que, según Udaondo, le da su carácter de censualista al clero subsidiado, y no de asalariado. El presupuesto de culto no es un favor, sino que significa para el autor "una renta abonada al acreedor legítimo". Además, tal cual lo expresara la Conferencia Episcopal en palabras de Rötjjer, los montos del presupuesto son irrisorios comparados con lo que sería una "justa retribución” por las propiedades e ingresos injustamente suprimidos. Esta tesis de la 
"compensación" como origen de los presupuestos de culto excede la realidad argentina y se hace presente también en el contexto francés. Así lo señalan María Elena Barral y Jesús Binetti (2014):

El aporte estatal -vigente hasta la ley de separación de Iglesia y Estado de $1905^{4}$ - fue concebido, al menos por algunos sectores, como contraparte de la nacionalización de los bienes eclesiásticos iniciada en noviembre de 1789, tras la aprobación del decreto propuesto por Mirabeau. Un estudio de 1859 sobre el "budget" de cultos en Francia expresaba con este argumento la noción de reparación: el reconocimiento de Roma del carácter irrevocable de la venta de los bienes nacionales comprometía a Napoleón a garantizar un tratamiento y un sostenimiento razonable a obispos y párrocos (p. 43).

Esta visión de las reformas rivadavianas -origen y causa, según estos autores, del presupuesto de culto-como un ataque frontal y declarado a la Iglesia católica es reafirmada unos años después por Guillermo Gallardo (1962) en su obra La política religiosa de Rivadavia. El autor analiza los pormenores de las disposiciones del ministro y caracteriza al mismo como proclive a aceptar falsedades como la igualdad de derecho de las religiones, negando el carácter de religión verdadera a la Iglesia romana. También le asigna a Rivadavia una visión utilitarista de la religión de la cual pretendía servirse en aquellos aspectos que le fueran útiles, negando el carácter trascendental de la misma y negando también cuestiones como la filiación jerárquica con Roma (pp. 222-236).

En contraposición a estas tesis que plantean a las reformas rivadavianas como un ataque contra la religión y al presupuesto de culto como una necesaria aunque incompleta restitución, investigaciones de autores que se alinean en la nueva historiografía de la Iglesia en Argentina intentaron profundizar el análisis de estas problemáticas estudiando cómo incidió, de hecho, el reemplazo del sistema de diezmos por un presupuesto de culto en los volúmenes de dinero percibidos por los distintos actores de la institución.

Un primer aspecto a tener en cuenta en este sentido es el de la complejidad del sistema de rentas que sostenía al culto católico durante la colonia y los primeros años del periodo independiente. En términos de Roberto Di Stefano (2013a):

\footnotetext{
${ }^{4}$ Tuvo su inicio en el concordato de 1801
} 
... en época colonial el sistema de rentas que sostenía el culto, la pastoral, el gobierno y la justicia eclesiásticos era plural y enmarañado, dependía de una multiplicidad de fuentes, era administrado por diversas autoridades -civiles y eclesiásticas- y contenía muy diferentes tipos de contribuciones, algunas obligatorias y otras voluntarias, algunas provenientes de réditos de capitales y otras de la producción, sea artesanal o agrícola (p. 181).

Dentro de este complicado sistema, un lugar primordial lo tenían los diezmos. El sistema decimal de Buenos Aires, sin embargo, no estaba destinado a cubrir todos los gastos del culto, sino que excluía a los párrocos, quienes obtenían sus ingresos de los denominados derechos de estola o de altar. Los diezmos se utilizaban para la manutención del alto clero y para la fábrica de las iglesias matrices, entre otros destinos. Pero lo que complicaba aún más el sistema rentístico era la creciente conflictividad suscitada por el sistema de cobro de las rentas decimales en la provincia de Buenos Aires durante las primeras décadas del siglo xix. Peire y Di Stefano (2004) demuestran que si bien los montos totales de los diezmos no disminuyeron, sino que aumentaron durante los años previos a 1822, el problema se centró en las formas de distribución que dejaban a muchos eclesiásticos sin un sustento suficiente.

A partir de los datos, los autores plantean que factores como: a) las fluctuaciones en los volúmenes de las cosechas -de los cuales provenían diezmos y primicias-; b) la reorientación de la producción bonaerense hacia el sector ganadero, que no pagaba primicias; c) la administración civil de los recursos provenientes de estas fuentes por parte de la monarquía y los gobiernos independentistas, $\mathrm{y}$ d) la desarticulación de los canales de cobro por los conflictos con la corona y la posterior guerra civil, provocaron que el reemplazo de los diezmos por un presupuesto de culto significara una "medida de rescate" más que "un duro golpe para el alto clero porteño". Claro que ese rescate no estaría destinado a subsanar los supuestos males provocados por las reformas rivadavianas con la supresión del pago del diezmo y las expropiaciones de inmuebles pertenecientes a instituciones católicas, sino a contrarrestar los añejos problemas de percepción y distribución de recursos recientemente mencionados.

Miranda Lida (2007a), por su parte, abona a esta hipótesis del salvataje al considerar que luego de la independencia, "los diezmos se habían convertido en un impuesto que resultaba arcaico y sumamente difícil de recaudar. En este marco, la supresión de los diezmos fue recibida con beneplácito por la Iglesia, sin despertar mayores resistencias". 
Por su parte, Barral y Binetti (2014) hacen énfasis en la supuesta incompatibilidad entre un gobierno -el de Martín Rodríguez- que se presentaba como modernizador y secularizador y la instauración en la provincia de Buenos Aires de un presupuesto de culto; es decir, en el hecho de que los gobiernos bonaerenses hayan tomado la decisión de sostener económicamente al culto católico. Para los autores, la regulación estatal de los aportes para el culto forma parte de un proyecto más amplio de delimitación institucional de la Iglesia católica -es decir, un proyecto secularizador- que permitiera eliminar "la poliarquía barroca" y controlar "el margen de acción de instituciones y agentes" (p. 64).

Pero claro que el presupuesto de culto no afectaba por igual a todos los miembros del clero. Como aclaran Peire y Di Stefano, la medida de rescate que significó el presupuesto de culto se limitó a solventar los gastos del "alto clero porteño", no logrando paliar la situación de precariedad que atravesaba el resto del clero porteño y bonaerense. Sobre esta problemática trata el artículo de María Elena Barral (2010), que pone en duda esta idea del "salvataje" estatal al personal eclesiástico mediante el presupuesto de culto, ya que el mismo, al transitar los mismos canales que los diezmos, dejaba excluidos a los párrocos de campaña, que no se veían beneficiados por el nuevo sistema: "Este presupuesto también sostenía casi exclusivamente a las instituciones de gestión eclesiásticas con sede en la ciudad de Buenos Aires. Así, el recorrido de la distribución del presupuesto de Culto transitaba por los mismos itinerarios que el suprimido diezmo" (p. 16).

Por otra parte, Di Stefano se encarga también de poner en cuestión el supuesto que subyace de las mencionadas obras de Udaondo, Rötjjer y Gallardo, que explica la existencia del presupuesto de culto como consecuencia de la expropiación de bienes producida durante las reformas rivadavianas. La puesta en funcionamiento de un presupuesto de culto en la época de la Confederación sin una previa expropiación similar da prueba de lo frágil de esa lógica de sustitución. Además, los volúmenes de los presupuestos que se analizarán más adelante, tanto en la Confederación Argentina como en Buenos Aires, no alcanzaban ni mucho menos para cubrir los gastos del culto en su totalidad. Es, plantea Di Stefano (2010), la existencia del derecho de Patronato y el interés en su conservación por parte de los gobiernos posindependentistas lo que explicaría esa contraprestación económica.

En realidad, su existencia [la del presupuesto] está vinculada indisolublemente a la vigencia del derecho de patronato [...]. En la época de la reforma rivada- 
viana a casi nadie se le pasaba por la cabeza la idea de poner fin al patronato separando la Iglesia del Estado e interrumpiendo el sostén económico estatal. Es decir, el presupuesto de culto se relaciona con el patronato, no con las confiscaciones ni con la abolición del diezmo.

Esta tesis de Di Stefano, sobre la cual volveré al analizar el caso de Tucumán, es discutida por Juan Navarro Floria en un artículo publicado en Criterio en 2011, que hace foco en el texto de la Ley de Supresión de los Diezmos en la provincia de Buenos Aires en 1822, en el contexto de las mencionadas reformas rivadavianas. En el artículo $2^{\circ}$ de dicha ley consta lo siguiente: "Desde el $1^{\circ}$ de enero de 1823 quedan abolidos los diezmos; y las atenciones a que ellos eran destinados serán cubiertas por los fondos del Estado" (Navarro Floria, 2011). Es decir que, por lo menos desde lo declamatorio, el carácter de compensación está presente en el origen del presupuesto, más allá de que las intenciones de las autoridades civiles fueran las de garantizar la continuidad del ejercicio del patronato sobre el personal eclesiástico, tesis con la cual se concuerda en este trabajo.

Las reformas rivadavianas tuvieron para Di Stefano (2008) otra consecuencia relevante que señala al mismo tiempo uno de sus objetivos centrales. Según este autor, la Ley de 1822 "confirió a las instituciones religiosas esa organización unitaria, las incorporó a la estructura político-administrativa del Estado en formación y con ello las expropió a la sociedad que las había creado y había garantizado su reproducción hasta entonces" (p. 507). En el mismo registro secularizador que plantean luego Barral y Binetti, al arrancar las instituciones del culto católico de manos de las familias de la elite porteña, la reforma "sentó las bases de la Iglesia contemporánea, que dio con la reforma sus primeros pasos en la mayor de las provincias argentinas para extenderse, tras la unificación nacional, al conjunto del país" (Di Stefano, 2008, p. 507).

\section{EL PRESUPUESTO DE CULTO A NIVEL NACIONAL. LA CONSTITUCIÓN DE 1853}

\section{El sostenimiento del culto}

El presupuesto de culto en el resto de Argentina se instauró a partir de 1853 con su inclusión en la Constitución bajo la figura del "sostenimiento" del cul- 
to católico. ${ }^{5}$ Esta fórmula del sostenimiento vino a significar una solución de compromiso tendente a evitar los extremos que representaban un Estado decididamente laico y un Estado confesional. La adopción de una religión de Estado hubiera significado para los detractores de esa idea la incongruencia de que un colectivo de personas adopte, cual si fuera un individuo, una religión como propia. En este sentido, los opositores retomaban la argumentación previamente planteada por Esteban Echeverría (2003): "El Estado, como cuerpo político, no puede tener una religión, porque no siendo persona individual, carece de conciencia propia" (p. IV). Por otra parte, el principio de la libertad para profesar otros cultos, a esa altura ya establecido e indiscutible, se volvía, para esta vertiente, inconciliable con la idea de una religión de Estado (Echeverría, 2003, p. IV). ${ }^{6}$

Por su parte, quienes proponían una fórmula de estilo tradicional, es decir la proclamación del catolicismo como religión de Estado, no pretendían, según Abelardo Levaggi, imponer su voluntad por la fuerza a los no católicos sino dejar asentado el hecho de que la mayoría de la población era católica, por lo cual los poderes públicos debían asumir el compromiso de respetar esa religión (Levaggi, 1994, p. 206). Y a tono con lo planteado anteriormente por Udaondo, Rötjjer y Gallardo, Levaggi (1994) también considera a este aporte estatal no una "liberalidad" del Estado, sino "el cumplimiento de una contraprestación a que se obligaron sucesivos gobiernos por haber desapoderado a la Iglesia de muchos de sus bienes mediante la abolición del diezmo, la confiscación de bienes conventuales y la redención de capellanías" (p. 207).

Por otra parte, la figura del sostenimiento del culto se presentaría luego como ambigua, ya que en el contexto de resoluciones futuras debía establecerse la naturaleza y el alcance de ese sostenimiento. ¿Se trataba de un mero aporte económico o implicaba un compromiso de protección y propagación de la religión católica mediante las instituciones del Estado? Para Levaggi (1994), si bien la Corte Suprema decretó que el término "sostiene" hacía sólo referencia a que los gastos del culto deberían cubrirse mediante los fondos del tesoro nacional, otros artículos concordantes del propio texto constitucional venían a poner en cuestión cualquier tipo de suposición de neutralidad del Estado en materia religiosa. Entre esos artículos figura el 67, inciso 15, que

5 Artículo 20: "el Gobierno Federal sostiene el culto católico apostólico romano".

${ }^{6}$ Este particular se encuentra desarrollado más extensamente en Di Stefano y Zanatta (2000, p. 277). 
planteaba que el Congreso Nacional debía promover la conversión de los indígenas al catolicismo; el inciso 19 del mismo artículo, que brindaba al poder legislativo la potestad de aprobar concordatos con la Santa Sede; o el artículo 76, que obligaba al presidente y vicepresidente a pertenecer a la comunión católica (p. 206). A esta argumentación en favor de la tesis "extensiva" del sostenimiento se puede agregar la elevación del catolicismo a "Religión de Estado" en el Código Civil elaborado por Vélez Sársfield y sancionado en 1869 (Di Stefano y Zanatta, 2009, p. 288). Para Roberto Di Stefano, en definitiva, es esa obligación a la cual se comprometió el Estado nacional de sostener el culto católico la que justifica la existencia del presupuesto de culto.

De todas formas, está claro también que el sostenimiento del culto tenía como objetivo la justificación del ejercicio del Patronato por parte del gobierno de la Confederación. Por lo tanto, este artículo $2^{\circ}$ debe ser comprendido de forma complementaria con los artículos $83^{\circ}$, que reserva al poder ejecutivo la potestad de presentar candidatos para las sedes episcopales previa propuesta de ternas por parte del Senado y el $64^{\circ}$, que además de instar al poder legislativo a promover la conversión de los indígenas, le reservaba a este la atribución de dar pase a los documentos papales (Martínez, 2013, p. 368).

La conformación de un presupuesto de culto a nivel nacional, según lo dispuesto por la Constitución y la consecuente eliminación del sistema de diezmos significó, en términos de Miranda Lida (2007a), un problema para las administraciones provinciales, ya que las mismas habían dispuesto de esos ingresos, los cuales habían manejado a discreción durante todo el periodo de las autonomías provinciales. Es por ello que el reemplazo del tradicional sistema por un presupuesto de culto no debe abonar, según la autora, a la tesis del enfrentamiento propuesta por algunos autores analizados anteriormente, sino que puede aportar para la comprensión del problema de la construcción conjunta de dos instituciones que a mediados del siglo xix no había todavía definido claramente sus límites ni sus atribuciones: la Iglesia y el Estado. En este sentido, la abolición de los diezmos como un ingreso del cual hacían uso las provincias de manera arbitraria y su reemplazo por un presupuesto nacional de culto deben ser entendidas "a la luz del problema de la formación del Estado central" y su puja con los poderes locales:

Más bien, desde nuestra perspectiva, la creación de aquel presupuesto se halla estrechamente relacionada con el propio proceso de la formación del Estado y de la construcción, en paralelo, de la Iglesia nacional: no se puede olvidar que 
ni la Iglesia ni el Estado se hallaban plenamente constituidos o consolidados en la Argentina a la hora en que el presupuesto nacional de culto veía la luz en 1853 (Lida, 2007a).

Al mismo tiempo, plantea la autora, la creación del presupuesto de culto fue también una posibilidad para el nacimiento de una "Iglesia nacional", ya que permitía superar los conflictos y las "tendencias centrífugas" de las iglesias provinciales provocados por la escasez de rentas y la incongruencia entre las geografías eclesiástica y civil. Siguiendo a Di Stefano, Lida plantea que así como las reformas rivadavianas permitieron a las autoridades porteñas "inventar" la Iglesia en Buenos Aires, otro tanto sucedió con posterioridad con las iglesias de la Confederación.

En definitiva, la supresión de los diezmos y la formación del presupuesto estatal de culto en 1853 se vincula entonces con dos problemas que son clave para la comprensión de la historia de la Iglesia luego de 1853: por un lado, como ya hemos advertido, la formación del Estado; por otro lado, la propia construcción de una Iglesia, hasta entonces sumamente desdibujada, que debió emprender una larga marcha hasta que logró cobrar una forma nacional (Lida, 2007a).

\section{Los presupuestos de culto de la Confederación Argentina $y$ del Estado de Buenos Aires}

Entre 1852 y 1861, el territorio de la actual República Argentina se dividió en dos estados soberanos: la Confederación Argentina y el Estado de Buenos Aires. ${ }^{7}$ Como parte de la asunción de sus atribuciones soberanas, ambas entidades políticas se hicieron cargo de los gastos generados por la práctica del culto católico en su territorio, dando origen a dos presupuestos de culto de disimiles características. Miranda Lida (2007a) ha propuesto comprender las variaciones entre ambos presupuestos como resultado de dos distintas for-

${ }^{7}$ La Confederación Argentina reunía a las trece provincias que en ese momento conformaban el territorio y era presidida por el entrerriano Justo José de Urquiza. Buenos Aires, por su parte, se transformó en un Estado independiente que asumió sus relaciones con el mundo como una nación soberana, emitió su propia moneda y redactó su propia Constitución en 1854. 
mas de entender el lugar de la Iglesia en vida pública, y las responsabilidades del Estado y la sociedad para con la institución.

Por un lado, el presupuesto, "sumamente generoso" -cercano, según Lida, 13\% del total-, de la Confederación y la creación de un ministerio cuya tarea específica era la administración de esos recursos, son clara muestra de un gobierno "sensible a las materias eclesiásticas. El objetivo detrás de esta generosidad, plantea Lida, era la construcción de una Iglesia "uniforme, piramidal y centralizada" que, independizándose de la cabecera eclesiástica porteña funcionara a su vez como un impulso para la construcción del Estado de la Confederación Argentina.

En cuanto a los ítems atendidos desde el erario nacional, el presupuesto de culto de la Confederación estaba compuesto por sueldos para las iglesias catedrales, entre los que destacan los asignados a la recientemente creada diócesis de Paraná, ${ }^{8}$ que incluía a diez canónigos, sacristanes, capellanes, y otros cargos menores; sueldos para los párrocos de las iglesias matrices y partidas para cubrir los gastos del culto y la refacción de templos en las provincias que no fueran cabeceras de obispados.

En Buenos Aires, por otro lado, el presupuesto de culto posterior a la secesión no alcanzó nunca la generosidad del de la Confederación, según Lida (2007a), el mismo rondaba el $2 \%$ del presupuesto total, y esta falta de generosidad no sería explicable debido a un mayor avance del proceso de secularización en la ciudad portuaria, como una teoría tradicional de la secularización podría hacer suponer, sino por una diferente concepción sobre el origen del cual debían provenir los recursos que solventaran la práctica del culto católico. Mientras la Confederación respondiera más a un modelo francés de "religión de Estado", en el cual la Iglesia debía estar integrada en el aparato estatal, Buenos Aires se inclinaría por un modelo de tipo británico, en el cual debían ser los propios fieles los responsables de sostener su culto, con una menor o nula participación del Estado, que era pensada, de cualquier manera, como un auxilio ante la incompletitud de los propios recursos de la institución.

Este modelo binario propuesto por Lida fue sin embargo discutido posteriormente por otros autores. Roberto Di Stefano puso en cuestión la escasa

${ }^{8}$ La creación de esta diócesis en 1859 fue consecuencia de las negociaciones de Urquiza con la santa sede originadas por la necesidad de contar con una cabecera episcopal dentro del territorio confederado, ya que las provincias de Entre Ríos, Santa Fé y Corrientes dependían eclesiásticamente del obispado de Buenos Aires, en ese entonces fuera de la Confederación. Sobre la creación de la diócesis de Paraná, véase Bruno (1975, pp. 310-328). 
generosidad del presupuesto de culto bonaerense con posterioridad a 1852, realizando primero un contraste con los tiempos rosistas ${ }^{9}$ que demuestran que los presupuestos sufrieron un "aumento abrupto" a partir de esa fecha e incluyendo en el análisis "las innumerables erogaciones 'extraordinarias' que el Ministerio de Gobierno acordaba en beneficio de instituciones varias -cofradías, parroquias, conventos-y de los curas o capellanes". Estos elementos demuestran, para el autor, que había un acuerdo entre "la mayor parte de los protagonistas -eclesiásticos y laicos, clericales y anticlericales, masones y antimasones- respecto al deber del Estado de financiar el culto y la pastoral" (Di Stefano, 2013a, p. 196).

Por otra parte, Ignacio Martínez ha llamado la atención sobre este modelo binario proponiendo revisar la "generosidad" del Estado de la Confederación Argentina. Para el autor, lo relevante no es centrar el análisis en los presupuestos discutidos y votados en el parlamento, sino en lo que realmente hubiera sido ejecutado al finalizar el año fiscal. Según esta óptica, si bien es clara la intención galicana del gobierno confederado, los montos del presupuesto de culto efectivamente ejecutados -que llegaron en ocasiones, por ejemplo en los años 1857 y 1858 , a menos de $50 \%$ de lo presupuestadono permitirían aseverar de manera tan taxativa una contraposición entre este modelo de presupuesto y el porteño (Martínez, 2015). A su vez, esta "sub-ejecución" del presupuesto no queda reducida a la mera incapacidad por parte del Estado de asumir los gastos comprometidos, sino que radica en la lógica de funcionamiento, ya que lo que se presupuestaba no era lo que efectivamente debía aportarse, sino lo que el poder legislativo habilitaba al ejecutivo para destinar al culto.

A continuación se propone analizar la puesta en funcionamiento de un presupuesto de culto estatal en la provincia de Tucumán durante la segunda mitad del siglo xix. La intención que subyace tras este análisis es la de poder comprender, más allá de las discusiones conceptuales sobre la naturaleza y justicia de estos aportes, cómo funcionó en la práctica este tipo de sustento económico estatal a la Iglesia, en el contexto de una provincia que no era en esa época cabecera de obispado y que a su vez atravesó, durante dicho perio-

${ }^{9}$ Hace referencia a los sucesivos gobiernos de Juan Manuel de Rosas al frente de la provincia de Buenos Aires entre 1835 y 1852. Rosas fue a su vez la figura central de la Confederación Argentina durante dicho periodo, que finalizó con su derrota en manos de una alianza internacional liderada por Urquiza en la batalla de Caseros, en febrero de 1852. 
do, un crecimiento económico formidable, que redundó en la construcción de un aparato administrativo provincial que fue el reflejo visible de la paralela construcción del Estado en Tucumán.

\section{UN ESTUDIO DE CASO: TUCUMÁN EN LA SEGUNDA MITAD DEL SIGLO XIX ${ }^{10}$}

La vicaría foránea de Tucumán, circunscripción eclesiástica coincidente con los límites provinciales, formaba parte del Obispado de Salta desde su creación, en 1806, hasta la división y consecuente erección de la Diócesis de Tucumán, en 1897. Es decir que era, como muchas otras, una provincia sin obispo, lo cual provocaba -para criterio de la jerarquía de la Iglesia- una excesiva injerencia de los gobiernos civiles en los asuntos propios de la institución, como los nombramientos de párrocos y la distribución y administración de los diezmos. Estas prácticas se acentuaban aún más en los periodos de vacancia, cuando el obispado era administrado por un provisor nombrado por el Cabildo Capitular (Ábalo, 2013a, pp. 115-117).

La historia del presupuesto de culto en Tucumán inicia con la organización constitucional del Estado provincial a partir de 1852. Desde ese año se produjo un realineamiento de las provincias del interior en favor de la naciente Confederación Argentina presidida, desde la ciudad de Paraná, en Entre Ríos, por Urquiza. En Tucumán, el gobernador Celedonio Gutiérrez se encolumnó tras la figura de Urquiza al encargar, por decreto del 25 de marzo de 1852, al gobernador entrerriano la responsabilidad para "entretener las Relaciones Exteriores y los negocios generales de la Confederación Argentina" (Cordeiro y Viale, 1915-1919, vol. I, p. 10). A partir de 1852, la provincia iniciaría un proceso de varias décadas de consolidación institucional aunque con una marcada inestabilidad política, fruto de las continuas contiendas entre facciones que redundaron en repetidas asonadas e interrupciones violentas de los gobiernos. Los hitos que señalaron el inicio de esta consolidación institucional fueron la promulgación del Estatuto Provincial el 6 de noviembre de 1852 y la sanción de la Constitución de la provincia a fines de 1856 (Páez de la Torre, 1987, p. 506).

${ }^{10}$ Para un panorama más completo sobre el presupuesto de culto en Tucumán, véase Ábalo (2013b). 
Por otra parte, la segunda mitad del siglo xix fue también el periodo del despegue de la economía provincial, gracias al desarrollo de la industria azucarera que provocó una reorientación de la actividad local, que pasó de la diversificación al casi completo monocultivo de la caña de azúcar. ${ }^{11}$ Este viraje se tradujo muy pronto en una revitalización de la economía que comenzó a demandar mano de obra para el surco y los ingenios, la cual fue cubierta en parte con migrantes, transformando a Tucumán en un área receptora de nuevos habitantes a partir de 1870. Esta década sería también la que propiciaría el despegue definitivo de la industria azucarera, gracias a la incorporación de nuevas tecnologías y a las oportunidades brindadas por la llegada a Tucumán del ferrocarril, ${ }^{12}$ lo cual abarató la importación de maquinarias y bajó los costos del flete para la comercialización de la producción. Este acelerado crecimiento de la economía tucumana tuvo su correlato en el fuerte incremento de los recursos económicos de la provincia y, por consiguiente, también en los gastos del erario público que se verían contemplados en los presupuestos provinciales.

Para poder canalizar este incremento de la circulación de dinero hacia las arcas provinciales, se asistió durante la segunda mitad del siglo a una modernización del sistema impositivo que pasó de basarse en los impuestos al tránsito y al comercio a depender casi exclusivamente de la renta a la producción, en este caso azucarera. Desde inicios del siglo xIx, los ingresos del tesoro provincial provenían fundamentalmente de cuatro fuentes: Derechos de efectos del extranjero, Piso en la Ciudad y campaña, Derechos de exportación de frutos de la provincia, y Derecho de patentes. Se trataba de impuestos al tránsito comercial que eran muy comunes en la época colonial (Rex Bliss, 2004 , p. 34). Otro problema de este sistema, además de su inadecuación a las necesidades de la época era, como plantea Rex Bliss (2004), su falta de orden, ya que estaba formado por una multiplicidad de tributos que se superponían conformando un "conglomerado de disposiciones yuxtapuestas" (p. 22).

En el proceso de racionalización o modernización del sistema impositivo hubo una primera etapa en la cual se eliminaron los derechos de tránsito, que fueron reemplazados por la contribución directa, territorial y mobiliaria que fue una cesión del gobierno nacional llamada a llenar el vacío provoca-

${ }^{11}$ Sobre la industria azucarera tucumana de la segunda mitad del siglo XIX, véase Bravo (2008); Campi (2000); Guy (2008); Molina (1994); Sánchez Román (2005).

${ }^{12}$ La llegada del ferrocarril a la provincia se dio en el contexto de la presidencia del tucumano Nicolás Avellaneda al frente de la República Argentina, ahora ya unificada con la incorporación de la provincia de Buenos Aires a partir de 1861. 
do por la eliminación de las aduanas provinciales (Herrera, 2010, p. 187). La eliminación de aduanas interiores tuvo otro corolario que fue la necesidad de regularizar aportes del erario nacional para asistir a los déficits presupuestarios que se hicieron comunes en las provincias interiores. Por ejemplo, para el año 1865, para cubrir un presupuesto provincial de 77992 pesos, ${ }^{13}$ la provincia recibía de la nación un subsidio de 11294.04 pesos (Garavaglia, 2013, p. 22). Otras medidas que complementaron esta eliminación de aduanas interiores fueron la erradicación de las contribuciones forzosas y la eliminación de los diezmos en el año 1854 por parte del gobernador pbro. José María del Campo (Páez de la Torre, 1987, p. 519). El diezmo y las aduanas conformaban la mayor fuente de ingresos, y aunque no se cuenta con los montos discriminados que aportaba cada uno, se sabe por el proyecto de ley redactado por el poder ejecutivo para 1854 que entre los dos completaban una suma de entre 50000 y 60000 pesos al año, siendo así el principal recurso con el cual se contaba. ${ }^{14}$ En el presupuesto de 1854 los ingresos de la provincia quedaron reducidos a 17957 pesos, lo cual terminaba arrojando un déficit de 26436 pesos debido, según el gobernador del Campo, a la eliminación de esos impuestos antes mencionados. Está claro que, en Tucumán, los diezmos formaban parte importante de los recursos con los que contaba la provincia, lo cual respalda lo afirmado por Peire y Di Stefano cuando dan cuenta de las dificultades que provocaba a la Iglesia "la administración civil de los recursos provenientes de estas fuentes por parte de la monarquía y los gobiernos independentistas". También considero que este dato se encuentra en consonancia con la afirmación de Lida cuando plantea el "uso discrecional" que hacían los gobiernos provinciales de estos fondos antes de 1853.

Hacia el último cuarto del siglo XIX, el crecimiento de la economía provincial liderado por la producción de azúcar redundó directamente en un aumento de las rentas provinciales, ya que "los beneficios azucareros se presentaban como la fuente más obvia de ingresos para el erario provincial" (Sánchez Román, 2005, p. 249). Para aprovechar este crecimiento de la industria del surco se establecieron a fin de siglo una serie de contribuciones a pagar por parte de los ingenios de acuerdo con su tamaño y a su volumen de producción, además de producirse un incremento en las patentes por ingenio y

13 Véase el cuadro 1 del anexo.

14 Proyecto de Ley de Presupuesto del Poder Ejecutivo para el año 1854. Cordeiro y Viale (1915-1919, vol. I, p. 209). 
de la contribución en el rubro "Hectáreas de caña". Claro que los intereses del sector azucarero intentaron limitar esta "sobrecarga" impositiva en el sector, consiguiendo frenar repetidamente la imposición de un gravamen nacional al azúcar, aunque no lograron exceptuar del mismo a un importante derivado como lo era el alcohol de caña (Sánchez Román, 2005, p. 249).

Como consecuencia de esta modernización y adecuación del sistema impositivo en la provincia, los montos de los presupuestos provinciales se elevaron de forma significativa, pasando los recursos disponibles de un total de 8118.20 pesos en 1852 a 2556156 pesos en 1897. A su vez, esta multiplicación de los fondos también se tradujo en una complejización del aparato administrativo provincial que dependía de ese presupuesto. Mientras que el presupuesto de 1852 debía atender un total de nueve incisos y 67 artículos, en 1897 el presupuesto provincial contemplaba dos anexos que incluían 25 incisos y 484 artículos. ${ }^{15}$

En definitiva, como consecuencia del crecimiento económico experimentado por la provincia de Tucumán en la segunda mitad del siglo xix, que se apoyó fundamentalmente en el vuelco de la producción provincial al monocultivo de la caña de azúcar y la elaboración de derivados como azúcar y alcohol, hubo un aumento en los ingresos del erario público que fueron a su vez el resultado de la adecuación del sistema provincial de rentas a la nueva estructura productiva provincial. Considero que este crecimiento económico, el aumento de los ingresos públicos en Tucumán, y el gran crecimiento del presupuesto, deben ser considerados como las condiciones de posibilidad que permitieron a los sucesivos gobiernos provinciales encarar la tarea de construcción del aparato administrativo estatal, extendiendo su influencia a algunas actividades que hasta el momento habían escapado a ella. A continuación se analiza la atención prestada por el Estado tucumano a las instituciones de culto católico mediante la utilización de los recursos provenientes de las arcas provinciales. En los términos planteados, este regular aporte económico a la Iglesia católica puede ser pensado como un intento de controlar y supervisar la actividad de la institución por parte del Estado, una vez que este tuvo la posibilidad de hacerlo.

15 Para el presupuesto del año 1854, véase Cordeiro y Viale (1915-1919, vol. I, p. 61), y para el presupuesto de 1897, véase Sánchez Loria y Del Moral (1915-1919, vol. xxi, p. 53). 


\section{Las disposiciones de las constituciones provinciales de Tucumán sobre el culto}

Como consecuencia de lo estipulado por la carta magna en lo tocante al culto, las provincias tuvieron que adecuar sus estatutos provinciales a lo dispuesto en la Constitución de 1853. Las provincias fueron emplazadas a presentar sus constituciones adaptadas a la nacional, cosa que hicieron entre 1855 y 1856 (Lanteri, 2011, pp. 78-85).

En el caso de Tucumán, se redactaron durante la segunda mitad del siglo xIX dos constituciones provinciales: la mencionada en 1856 y en 1884. En la primera de ellas, el artículo $4^{\circ}$ estipulaba: "Las autoridades de la provincia deben especial protección a la religión católica apostólica romana, que profesa el pueblo, sin perjuicio de la libertad de cultos establecida por la constitución nacional" (Cordeiro y Viale, 1915-1919, vol. I, pp. 383-384). ${ }^{16}$ Es decir que, además de asegurar el respeto a la libertad de cultos en consonancia con lo dispuesto por la nación, el Estado tucumano se comprometía a proteger a la religión católica. Esta protección, como se verá en el ulterior accionar de los gobiernos tucumanos, implicó, durante la segunda mitad del siglo, un aporte continuo para el sustento económico de la Iglesia.

Por su parte, la Constitución provincial de 1884 decía, en su artículo $3^{\circ}$, que "El gobierno de la provincia cooperará al sostenimiento del culto Católico Apostólico Romano con arreglo a las prescripciones de la Constitución Nacional" (Cordeiro y Viale, 1915-1919, vol. x, p. 567). Aquí la referencia es más precisa, ya que el término "sostenimiento" tenía una más clara connotación económica, y además se aclaraba que se trataba de una cooperación; es decir que la provincia no se haría cargo del sostenimiento del culto, sino que cooperaría con el mismo. En los términos analizados anteriormente en la comparación entre los presupuestos de culto de la provincia de Buenos Aires y la Confederación, Tucumán se inclinaría por un modelo que, según Lida, podría caracterizarse como "británico", cuya intención era hacer recaer en la iniciativa privada y en la feligresía la mayor parte del costo que implicaba el ejercicio público del culto católico.

${ }^{16}$ La idea de la protección que los gobiernos provinciales debían a la Iglesia católica apareció también en las constituciones de Catamarca (1855), Córdoba (1855) y Santa Fé (1856), donde además se aclaraba que la católica era la religión de la provincia. Las de San Luis (1855) y La Rioja (1855) utilizaron la fórmula “adopta y sostiene”. Levaggi (1994, p. 207 y ss.). La cursiva es mía. 


\section{El destino de los fondos ${ }^{17}$}

Al no tratarse, en el caso de Tucumán, de una provincia que tuviera una sede diocesana como sucedía con Buenos Aires, o Paraná, Tucumán no contaba con una Curia eclesiástica cuyos cargos debiera solventar el Estado a partir de la eliminación del sistema de diezmos. Por lo tanto, los destinos de los fondos provinciales variarán respecto a lo visto tanto por Lida como por Di Stefano y Martínez para Buenos Aires y la Confederación Argentina.

Como se detalla en la gráfica 1, la mayor proporción del dinero que el Estado tucumano destinó al culto católico estuvo dirigido a la construcción, refacción o culminación de templos dentro del territorio provincial.

Los aportes más cuantiosos y constantes en este rubro fueron destinados a las obras de las iglesias del centro de la ciudad. Santo Domingo, San Francisco, La Merced y la iglesia matriz. La matriz, posteriormente elevada al rango de catedral en 1897, estuvo en construcción desde 1848, acelerándose el proceso a partir de 1852 (Meyer, 2008, p. 47). Como se verá en el Anexo, cuadro 1, hasta fines de la centuria la obra seguía demandando aportes por parte del Estado provincial para su culminación. La iglesia de Santo Domingo, actual basílica de Nuestra Señora del Rosario, por su parte, inició su construcción en la década de 1860 y permaneció en obra hasta la década de 1880. Durante esos años recibió de manera continua aportes del Estado provincial para la conclusión de la obra. En el caso de San Francisco, el viejo edificio de la iglesia fue demolido en 1879, dándose inicio a la nueva iglesia. Ello explica la aparición de un subsidio del Estado provincial para ese templo a partir del año 1881, el cual se extendería por más de una década. Por último, el templo de Nuestra Señora de la Merced reinició sus obras en 1865, luego de un par de décadas de abandono, y fue concluida en la década de 1880.

Además se hizo regular, desde 1881, un aporte para los templos de campaña que osciló entre 400 y 2000 pesos. Las sumas destinadas a los templos tuvieron su pico más alto en los primeros años de este aporte, entre 1873 y

${ }^{17}$ Atendiendo al señalamiento realizado por Ignacio Martínez (2015) a los números del presupuesto de la Confederación Argentina planteados por Lida (2007a), hago la aclaración de que para el estudio de la provincia de Tucumán se utilizaron tanto los presupuestos que se presentaban a principio de cada año, como las rendiciones de cuentas que elevaba el ejecutivo todos los años -salvo contadas excepciones- al finalizar el periodo fiscal. Las variaciones entre lo presupuestado y lo ejecutado durante el lapso que contempla este trabajo resultan ínfimas y considero que no merecen ser tenidas en cuenta en este análisis. 
Gráfica 1. Destino de los fondos para el culto (1861-1897)

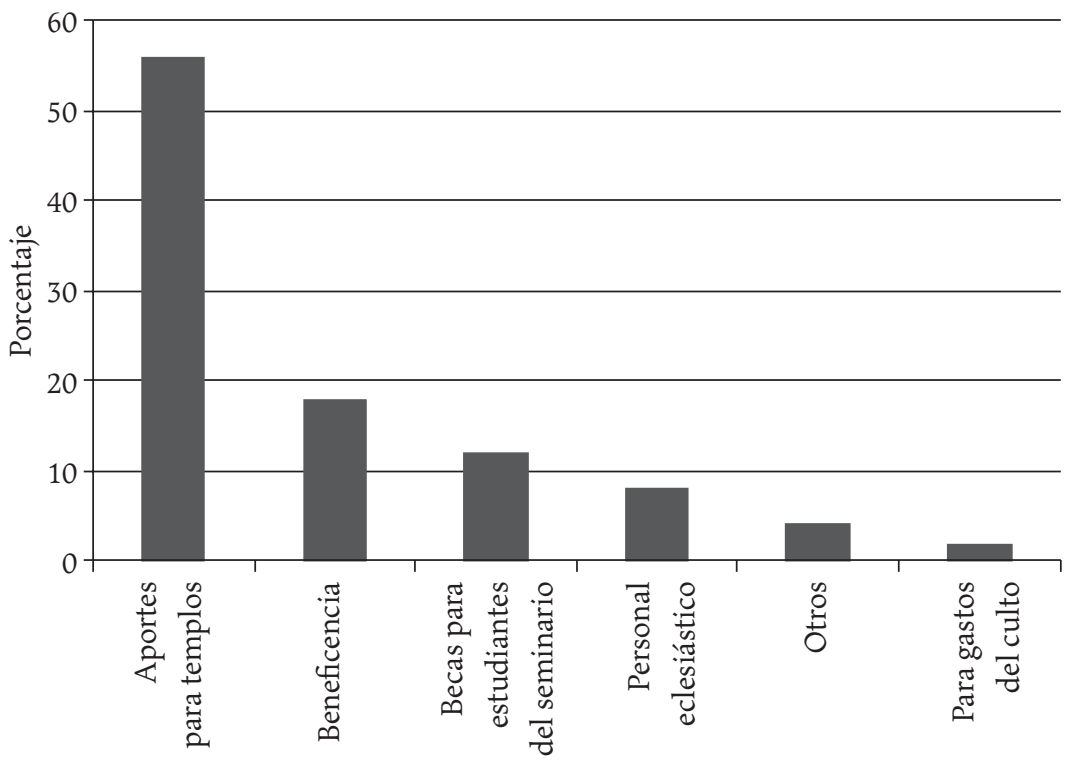

Fuentes: elaboración del autor a partir de los presupuestos provinciales que se encuentran en la Compilación ordenada de leyes, decretos y mensajes del periodo constitucional de la provincia de Tucumán. Años 1861, vol. II, p. 404; 1862, vol. III, p. 40; 1863, vol. III, p. 106; 1864, vol. III, p. 232; 1865, vol. III, p. 264; 1866, vol. III, p. 310; 1867, vol. III, p. 396; 1868, vol. IV, p. 13; 1869, vol. IV, p. $63 ; 1870$, vol. IV, p. $109 ; 1871$, vol. IV, p. $206 ; 1872$, vol. IV, p. $325 ; 1873$, vol. v, p. $53 ; 1874$, vol. v, p. $360 ; 1875$, vol. vi, p. 87 ; 1876, vol. vi, p. 183 ; 1877, vol. vi, p. 303; 1878, vol. viI, p. 85 ; 1881, vol. VIII, p. 88; 1882, vol. viII, p. 277; 1883, vol. IX, p. 226; 1884, vol. X, p. 97; 1885, vol. XI, p. 101; 1886, vol. XI, p. 266; 1888, vol. XII, p. 474; 1889, vol. XIV, p. 125; 1893, vol. XVII, p. 98; 1896, vol. XX, p. 76; 1897, vol. xx, p. 50.

1876, cuando les fueron aportados a los templos de Santo Domingo y La Merced 5000 pesos anuales a cada uno, llegando a significar entre ambos alrededor de $5 \%$ del total del presupuesto provincial.

Por otra parte, a partir de 1881 comenzaron a destinarse fondos a la obra de la iglesia matriz que necesitaba refacción, según declaraba el vicario general de la diócesis, Miguel Moisés Aráoz. La iglesia contaba con un fondo de 700 pesos y se esperaba contar hacia fin de ese año con un total de 2000 pesos (Sánchez Loria y Moral, 1915-1919, vol. viII, p. 79). La principal iglesia de la 
provincia recibió durante los años subsiguientes un aporte anual de entre 200 y 2000 pesos, llegando a la excepcional cifra de 5000 pesos en 1896, a poco más de un año de su elevación al rango de catedral. ${ }^{18}$

Como se puede percibir, el aporte para la construcción o refacción de templos fue constante y significativo durante los últimos 30 años del siglo XIX. Durante este periodo, el carácter "cooperativo" de los mismos, a tono con la Constitución provincial, fue una constante. El Estado provincial destinó fondos para templos en aquellos casos en los cuales estuviera garantizado el aporte de fondos y/o materiales mediante la iniciativa privada -generalmente suscripciones de vecinos. De esta manera se exigía a los solicitantes un subsidio -fueran estos vecinos de un pueblo de campaña, sacerdotes de alguna de las parroquias principales de la ciudad o miembros de una orden religiosaque demostraran con qué recursos contaban para iniciar la obra. ${ }^{19}$

Pero a su vez, dentro de este periodo hubo una evolución que, creo, responde al mencionado acrecentamiento de los recursos económicos de la provincia durante las últimas dos décadas del siglo. Por un lado, durante la década de 1870 y comienzos de la de 1880 el Estado provincial limitaba su participación a una mera "supervisión" del impulso que llevaban adelante las comisiones protemplo. Su tarea se limitaba a ratificar los nombramientos de los integrantes de las mismas, recibir los presupuestos que eran elaborados por las comisiones, destinar los fondos que se creyeran convenientes y pedir informes sobre el avance de la obra. Estas tareas se vieron acrecentadas hacia mediados de la década de 1880 cuando, mediante el departamento topográfico provincial, ${ }^{20}$ fue el Estado el responsable de evaluar cuál sería el emplazamiento de la obra de acuerdo con el estudio realizado por dicha dependencia.

Otra tarea del departamento topográfico pasó a ser la de evaluar los presupuestos que eran elevados al gobierno por parte de las comisiones. En el caso de que el presupuesto fuera rechazado, el mismo departamento se encargaba de la elaboración de uno nuevo, y de sacar a licitación la obra. Como puede apreciarse, la capacidad que daban los crecientes recursos al Estado

${ }^{18}$ Roberto Di Stefano (2013a) ha constatado también para Buenos Aires "una suerte de explosión de iniciativas orientadas a la refacción de viejos templos y a la construcción de otros nuevos" a partir de la caída de Rosas en 1852 (p. 183).

${ }_{19}$ Un análisis detallado de este tema en: Ábalo (2014, pp. 75-79). En la provincia de Buenos Aires se vivió un proceso similar que es analizado por María Fernanda Comas (2013, pp. 129-131).

${ }^{20}$ Fue creado en 1858. 
provincial provocó que se fueran limitando cada vez más los niveles de autogestión de las comunidades locales, absorbiéndose en la esfera estatal esas funciones (Ábalo, 2014, p. 76). Considero que esta evolución puede pensarse utilizando los términos planteados anteriormente por Barral y Binetti, y por Di Stefano, que señalan tanto una intención estatal de ejercer control sobre los actores institucionales de la Iglesia, como de expropiar a la sociedad ciertas instituciones -en este caso funciones- que tradicionalmente le incumbían. Este gobierno que "construye iglesias" nos coloca ante la disyuntiva de pensar si esos aportes económicos conforman parte de un proyecto secularizador, que pretendía trazar una frontera más claramente delimitada entre la Iglesia católica y la sociedad civil. ${ }^{21}$ Se trataría, en términos de Karel Dobbeleare, de un proceso de secularización cualitativa, comprendida como una descomposición de los regímenes de cristiandad, dando como resultado el nacimiento de una Iglesia y un Estado -y en el caso que analizamos, una sociedad-como entidades claramente diferenciadas. ${ }^{22}$

El segundo aporte más cuantioso está concentrado en el rubro Beneficencia. El mismo comenzó a aparecer en el presupuesto provincial a partir de 1893 y continuó figurando hasta el final del periodo que se contempla aquí. Este apartado incluía aspectos diversos que, pese a su heterogeneidad, pueden abonar a la hipótesis de la existencia de un acompañamiento por parte del Estado provincial a las iniciativas laicales que se enmarcarían en la categoría de asociacionismo católico.

Las instituciones beneficiadas con regularidad en este rubro fueron, por ejemplo, la Sociedad San Vicente de Paul, las terciarias franciscanas y dominicas, y las Esclavas del Corazón de Jesús. Además se erogaron algunos montos excepcionales como los 2500 pesos destinados a "un traje para la Virgen de la Merced”, en el año 1893. El destino de fondos por parte del erario provincial para estas asociaciones puede pensarse, siguiendo a Cynthia Folquer, como una delegación de tareas por parte del Estado provincial hacia esas asociaciones, en general femeninas, que se encargarían del "cuidado y protección de pobres y desvalidos", considerada esta como un "área de vacan-

${ }^{21}$ Queda pendiente para trabajos posteriores el estudio de los debates parlamentarios en la legislatura provincial que permitirán comprender mejor las motivaciones que dieron origen a los mencionados aportes, así como también los argumentos utilizados para sostener o criticar los mismos.

${ }^{22}$ Este planteamiento de Dobbelaere y un panorama general y actualizado sobre las teorías sobre la secularización, se encuentran en Mauro y Martínez (2015). 
cia" (Folquer, 2012, p. 109). Por otra parte, Folquer le asigna otro importante papel a esta tarea de beneficencia que recaía en las asociaciones católicas: "las élites gobernantes [...] tenían la convicción de que las mujeres entrarían en contacto con más facilidad con los sectores populares y suponían que las relaciones interclasistas -necesarias para el consenso- eran posibles si eran ejercidas por mujeres y, por lo tanto, eran ellas las que podían impedir revueltas y desórdenes sociales" (p. 111).

Otro aporte muy regular durante el último cuarto del siglo fue el que los gobiernos provinciales realizaban para colaborar con la formación de sacerdotes en el Seminario Conciliar de Salta. Este inciso fue incluido en los presupuestos desde el año 1875 y continuó sin interrupciones hasta 1897. Los montos tuvieron mínimas variaciones que fluctuaron entre 180 y 360 pesos por alumno, mientras que el número de beneficiados con este subsidio varió entre un mínimo de cuatro y un máximo de diez.

La inclusión de este aporte en el presupuesto tuvo su origen en una solicitud del obispo de Salta -diócesis a la que pertenecía la provincia de Tucumán-, Fray Buenaventura Rizo Patrón, quien comunicó al gobierno de Tucumán que el seminario diocesano había retomado sus funciones -después de su primera fundación en 1863 y su cierre en 1864- y que estaba listo para recibir seminaristas de las cinco provincias integrantes de la diócesis. La situación parecía ahora más propicia para el prelado, ya que además de la contribución proveniente de los fondos propios de la diócesis y de "nuestros amados diocesanos", se esperaba contar con el apoyo del gobierno nacional, quien "consecuente al deber de sostener el Culto Católico Apostólico Romano en la Nación, nos subviene [...] con los recursos para gastos, instalación y sueldo de profesores" (Cordeiro y Viale, 1915-1919, vol. v, p. 411). Quedaba, por lo tanto, instituido el seminario y a la espera de educandos. Con ese fin solicitaba Rizo Patrón al gobierno de Tucumán que apoyara esa iniciativa favoreciendo que "se eduquen en él algunos jóvenes de cuenta de esa Provincia" (Cordeiro y Viale, 1915-1919, vol. v, p. 414).

Al hacerse efectivo ese estipendio por parte del Estado tucumano de forma tan prolongada en el tiempo, ${ }^{23}$ puede percibirse que los gobiernos tucumanos consideraban que era propio de su incumbencia el colaborar con la formación del clero local, pensando en las necesidades de atención parroquial

${ }^{23}$ El subsidio para la formación de jóvenes tucumanos en el Seminario Conciliar de Salta se ejecutó de manera ininterrumpida entre 1875 y 1897. Véase el cuadro 1 del anexo. 
de la provincia y, sobre todo, en la lógica de un cierto control y manejo del personal eclesiástico por parte del poder civil. Cabe aclarar que, durante la segunda mitad del siglo xIX, los gobiernos provinciales como el tucumano, solían ejercer el vicepatronato dentro de sus territorios. Esta atribución le fue conferida por decreto del presidente de la Confederación, Urquiza, fechado el 1 de mayo de $1855 .{ }^{24}$ El vicepatronato permitía al gobierno nombrar y remover párrocos y beneficiados menores dentro de la provincia (Ábalo, 2013a), figuras que a su vez eran consideradas un vehículo de civilidad y de capacidad de gestión dentro de las comunidades. Aquí es donde la presente investigación respalda el planteamiento de Di Stefano, que afirma que es la lógica de la conservación del derecho de Patronato la que sustenta el aporte estatal para el culto -en este caso para su formación.

Un último grupo de aportes fueron englobados bajo el concepto de Personal eclesiástico. Se trata de un aporte constante por parte del Estado provincial para solventar los sueldos de dos eclesiásticos que cumplieron funciones dentro del aparato administrativo provincial: el capellán de gobierno y el notario eclesiástico.

El primero de estos dos funcionarios eclesiásticos aparece en los presupuestos provinciales desde el año 1863 con una asignación anual de 200 pesos. Esta cifra irá sufriendo modificaciones para terminar nuestro periodo de estudio ascendiendo a 1200 pesos. Según lo explicitado por el gobernador de la provincia en un mensaje al poder legislativo sobre el presupuesto, el capellán de gobierno era un empleado del Estado provincial que tenía como función oficiar misas tanto para las autoridades como también en el hospital y en la cárcel pública (Cordeiro y Viale, 1915-1919, vol. III, p. 223). La otra figura, el notario eclesiástico hace su aparición en las cuentas públicas de la provincia en 1885 con un sueldo de 240 pesos (Cordeiro y Viale, 1915-1919, vol. XI, p. 274). Su origen se inscribe en una disputa que se dio entre las autoridades civiles y eclesiásticas de la provincia debido a la creciente demanda, por par-

${ }^{24}$ El texto del decreto establecía: "los gobernadores de las provincias son Vice-patronos de las Iglesias fundadas en el territorio de su mando, y en calidad de tales ejercen, en delegación del Gobierno Nacional, el Patronato para la presentación y remoción de Curas, Beneficiados menores de las Iglesias Catedrales, habilitación de Capilla, erección y división de curatos y demás relativo al ejercicio de este derecho, como Vice-patronos dentro del territorio de su provincia". El decreto a su vez reservaba para el gobierno central el ejercicio del patronato; es decir, la potestad de nombrar cargos eclesiásticos "mayores" como los canónigos de las catedrales y también la posibilidad de realizar la presentación de obispos para su nombramiento por parte de la santa sede. El Nacional Argentino, núm. 179, 4 de marzo de 1855, p. 2. 
te del sistema judicial de la provincia, de expedición de partidas requeridas como prueba en procesos que se realizaban de oficio. Como en estos casos no había abogados litigantes que pudieran pagar la expedición de las partidas a los encargados de los registros parroquiales, un eclesiástico debía "distraerse" de sus tareas para atender estos casos, que, por lo referido por las autoridades eclesiásticas, no eran pocos. Si bien el asunto generó una fuerte discusión entre las autoridades civiles y eclesiásticas de la provincia, se resolvió hacer caso al pedido del vicario foráneo Ignacio Colombres, que solicitaba la retribución para poder destinar una persona específica para esta tarea.

Si bien estas dos figuras eran formalmente empleados estatales, su naturaleza era diferente. En el caso del capellán de gobierno se trata de una relación en la cual el patrono de la capellanía, es decir, el gobierno provincial, abona un estipendio al beneficiado, el capellán, como contraparte para la realización de ciertas tareas que tienen que ver con su oficio eclesiástico. ${ }^{25}$

El notario eclesiástico, sin embargo, era parte del engranaje del sistema de justicia. Y como fuera planteado en otro artículo (Ábalo, 2013a, p. 131), aporta una interesante plataforma para pensar el proceso de laicización en Tucumán en la segunda mitad del siglo xIx. Las partidas de nacimiento, matrimonio y defunción eran documentos públicos que el Estado provincial necesitaba para su correcto funcionamiento. Pero la administración y resguardo de los mismos estaba en manos de la Iglesia católica y era ejercido por funcionarios eclesiásticos. La creación de este puesto de notario eclesiástico introduce la novedad de que el Estado pague un salario a un eclesiástico para ejercer una función que se enmarca dentro del ámbito de la propia Iglesia hasta que los datos sean transferidos a la administración provincial en 1896, con la puesta en funcionamiento del registro civil. ${ }^{26}$ Se trata entonces de una etapa de transición en el proceso de laicización provincial en la cual el Estado no se hace cargo aún del registro civil, pero sustenta con sus fondos una parte de la administración del mismo.

En total, todos estos aportes fueron considerables dentro de los presupuestos provinciales de la segunda mitad del siglo xIX. Como puede verse con detalle en el cuadro 1 del anexo, la incidencia del presupuesto de culto en

\footnotetext{
${ }^{25}$ Sobre el funcionamiento de las capellanías, véase Gregorio de Tejada (1993, p. 63). El sistema beneficial fue estudiado en profundidad por Roberto Di Stefano (2004, pp. 55-59; 2013b).

${ }^{26}$ El Registro Civil de Tucumán fue creado por la legislatura provincial en 1890, pero no entró en funcionamiento sino hasta 1896.
} 
el total varió entre un mínimo de $0.19 \%$ en 1872 -año en que el aporte estatal al culto consistió sólo en el sueldo del capellán de gobierno-y un máximo de $5.34 \%$ en 1873, cuando los mencionados subsidios de 5000 pesos para la construcción de cada uno de los templos de La Merced y Santo Domingo elevaron los montos de ese presupuesto de culto. Contemplando los datos con los que se cuenta, el promedio del aporte estatal al culto ronda, durante la segunda mitad del siglo XIX, 1.55\% lo cual, siguiendo el modelo propuesto por Lida y discutido más arriba usando las objeciones de Di Stefano y Martínez, se acercaría más a $2 \%$ relevado por Lida para la provincia de Buenos Aires que al generoso 13\%, aunque sub-ejecutado, que llegó a establecerse en la Confederación Argentina. A su vez, los destinos que tuvieron estos aportes variaron respecto de los estudios mencionados, ya que Tucumán no tenía una sede episcopal que sostener en reemplazo de los diezmos. En general, el grueso de los fondos estatales apuntó más bien a facilitar la práctica del culto por parte de la población, por ejemplo en lo referente al cuantioso aporte para los templos de la provincia o los subsidios otorgados a las asociaciones laicales como las terciarias dominicas y franciscanas.

Los aportes para el culto en Tucumán continuarán más allá del límite del periodo aquí estudiado, es decir 1897, concentrándose básicamente en los aportes para beneficencia y no elevándose nunca por sobre $1 \%$ del total del presupuesto provincial.

\section{CONSIDERACIONES FINALES}

La existencia de aportes económicos por parte de los Estados, sean estos provinciales o nacionales, fue y es motivo de controversia tanto en el campo de los polemistas como en el de los académicos. La supuesta incompatibilidad de este aporte con la pluralidad de confesiones existentes en nuestro país ha llevado a sus detractores a considerar este presupuesto como un resabio del pasado y como una muestra de la malsana incomprensión del proceso de laicización en Argentina. Por otra parte, los historiadores confesionales destinaron sus esfuerzos a la justificación de estos aportes, intentando probar su carácter de reparación histórica como consecuencia de los continuos "saqueos" a que el Estado sometió a la Iglesia católica.

Como un intento de superar estas visiones sectarias, trabajos más recientes han propuesto centrarse en un análisis de las fuentes de financiamien- 
to de la Iglesia católica antes y después de la eliminación del sistema de diezmos y su reemplazo por un presupuesto de culto; de los montos destinados por los diferentes gobiernos al culto católico, y de los destinos que esos fondos tuvieron, como una forma de comprender qué concepciones eclesiológicas pueden encontrarse detrás de cada una de estas políticas públicas.

Considero que el estudio del caso del presupuesto de culto en la provincia de Tucumán en la segunda mitad del siglo xIx aporta la posibilidad de analizar la puesta en funcionamiento y la prolongación en el tiempo de un presupuesto de culto en un contexto determinado. El análisis de los presupuestos provinciales en un lapso de casi 40 años permitió corroborar que el marcado crecimiento de la economía provincial, sumado a la modernización y adecuación del sistema rentístico a la nueva estructura productiva, permitió un aumento significativo de los recursos del Estado provincial. A su vez, esos recursos disponibles hicieron que los diferentes gobiernos provinciales decidieran, con una llamativa continuidad, volcar una suma a veces muy importante de dinero para ayudar a solventar los gastos del culto católico, concentrándose en áreas como la edificación de templos, el asociacionismo católico y la formación de futuros sacerdotes.

A su vez, la figura del notario eclesiástico se plantea como interesante para avanzar en el estudio de ese periodo extenso de traslación de funciones entre la esfera eclesiástica y la civil, que no comienza ni termina con la sanción de las leyes laicas durante la década de 1880, sino que tiene sus antecedentes, como aquí se pudo ver, y también tendrá su corolario, durante las primeras décadas del siglo $\mathrm{xx}$.

Por otra parte, este aporte tan significativo debe servir para ayudar a poner en cuestión la tesis del enfrentamiento sin cuartel, a mediados y fines del siglo xIx, entre el catolicismo o la Iglesia católica y una elite gobernante ilustrada y laicista que pretendía acabar con los privilegios de la institución relegándola al espacio privado. En Tucumán se hace evidente que las elites provinciales, que tomaron las riendas de la política durante la segunda mitad del siglo xIX, consideraban relevante destinar fondos del erario provincial para construir iglesias, para formar sacerdotes, y para favorecer el asociacionismo de tipo católico; es decir, para construir la Iglesia. 


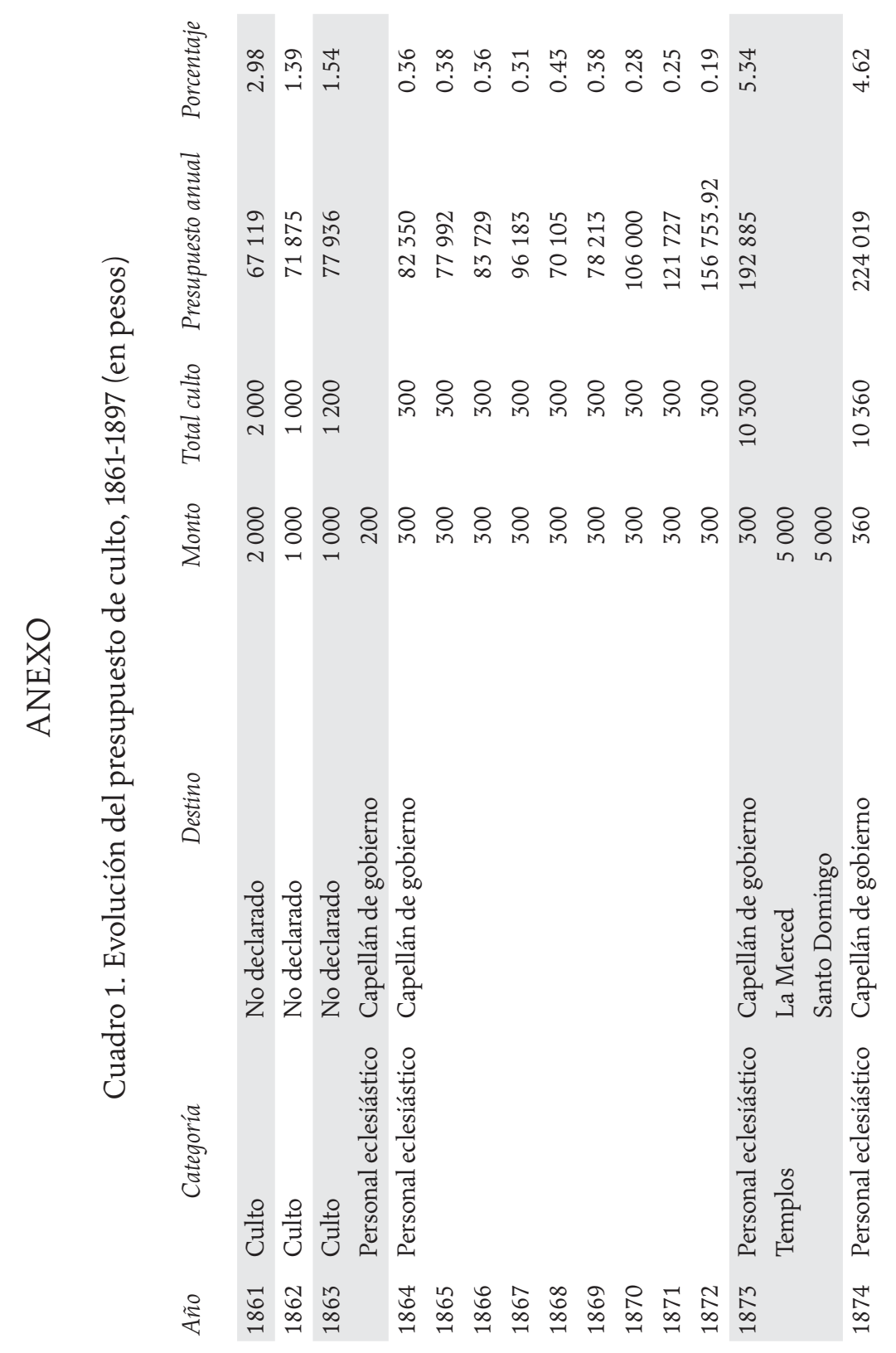




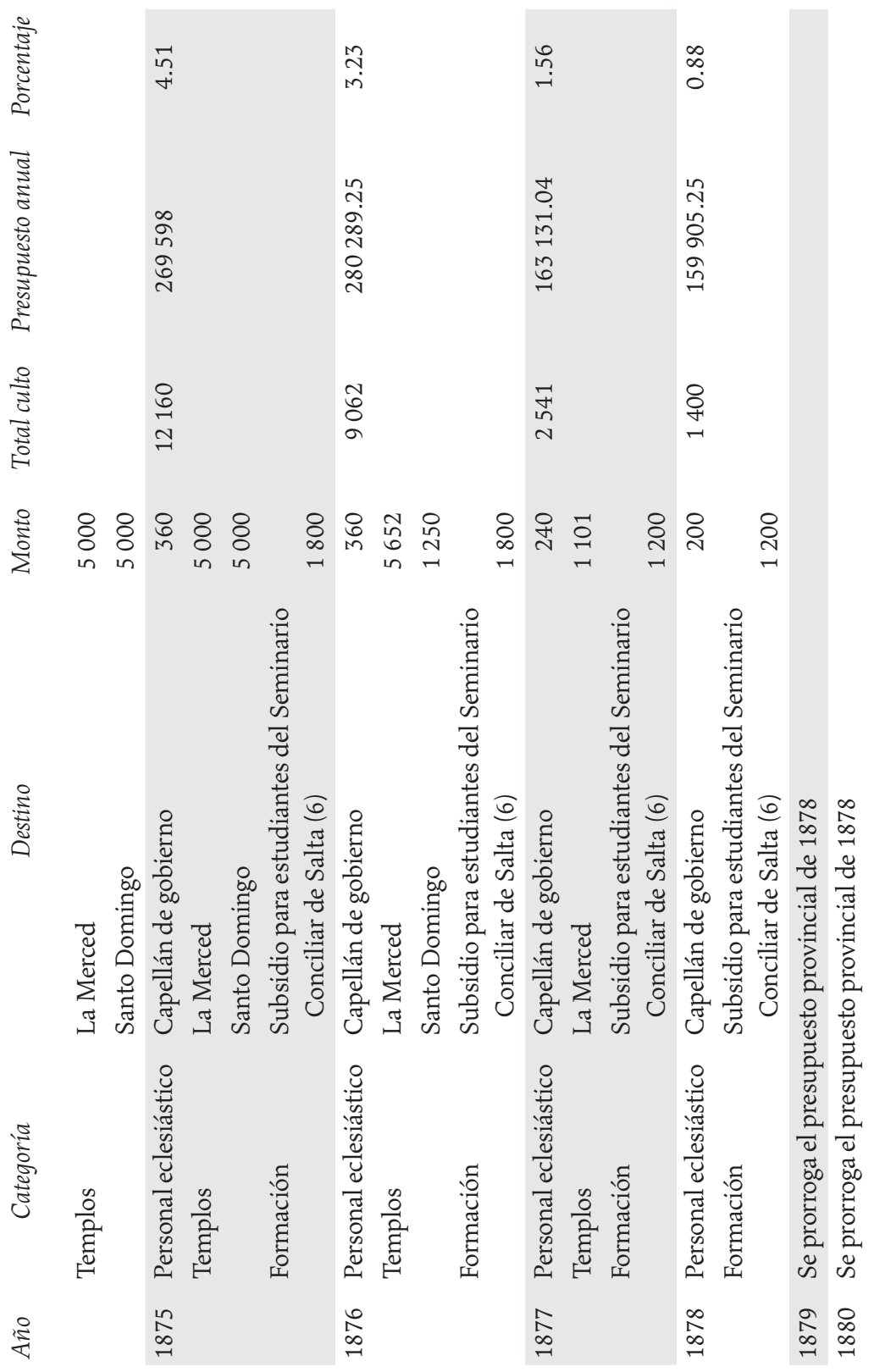



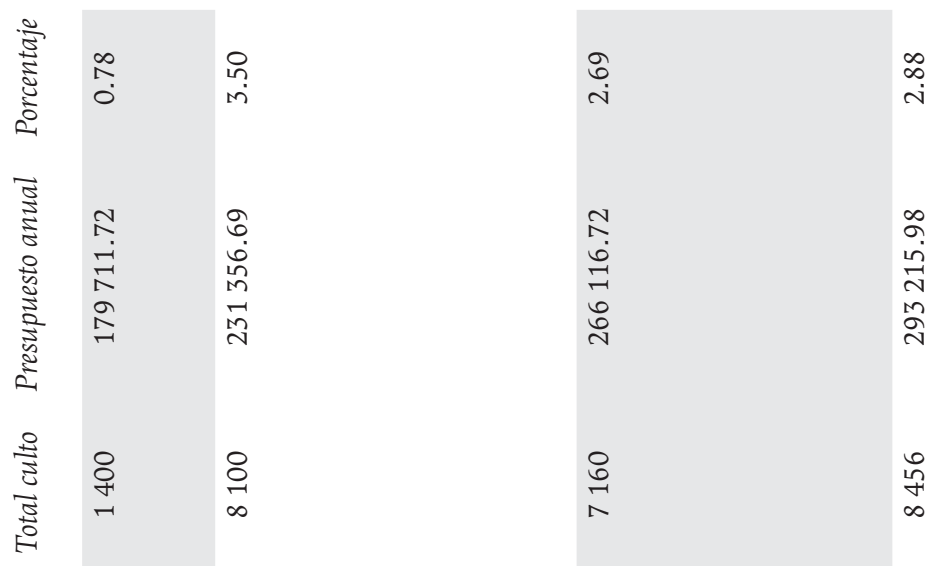

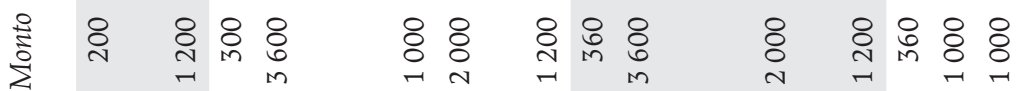
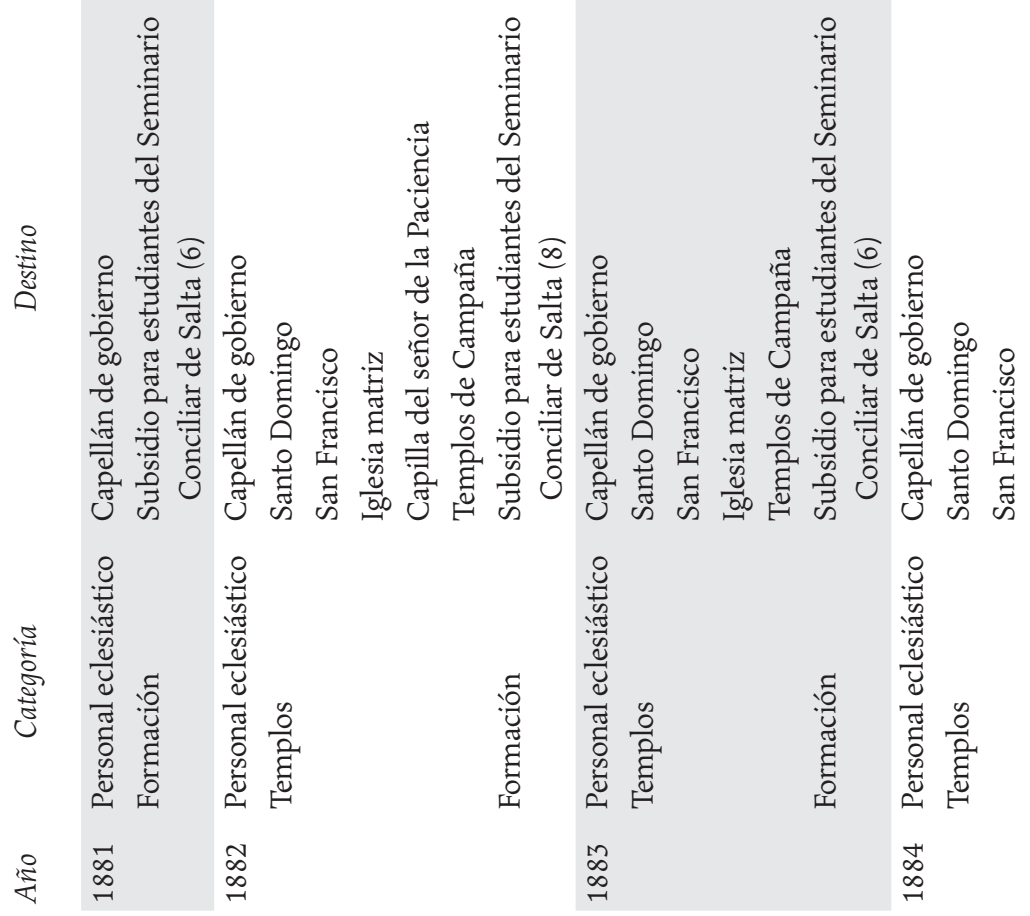
है
है
ป

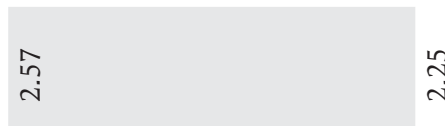

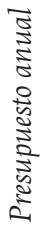

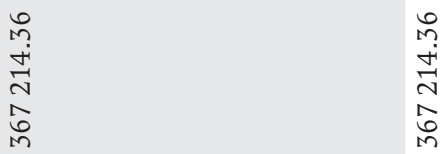

$\underset{\substack{0 \\ \stackrel{0}{0}}}{\stackrel{0}{0}}$

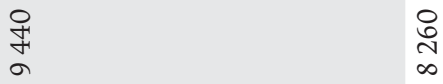

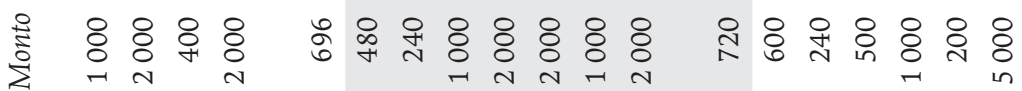

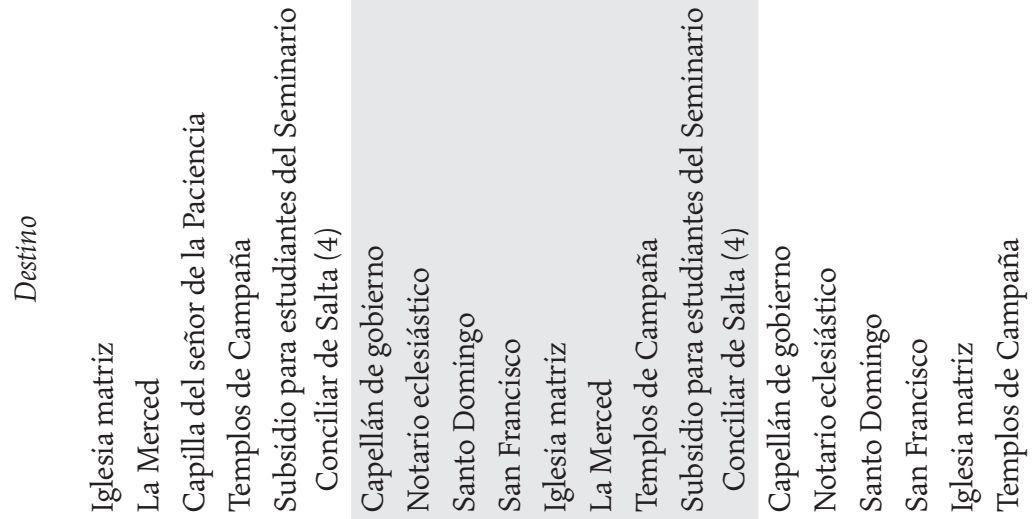

ș

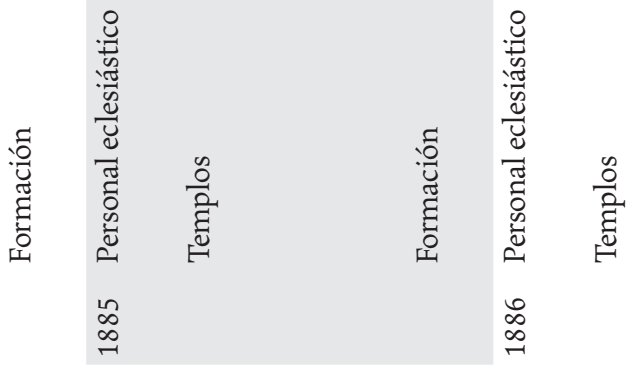



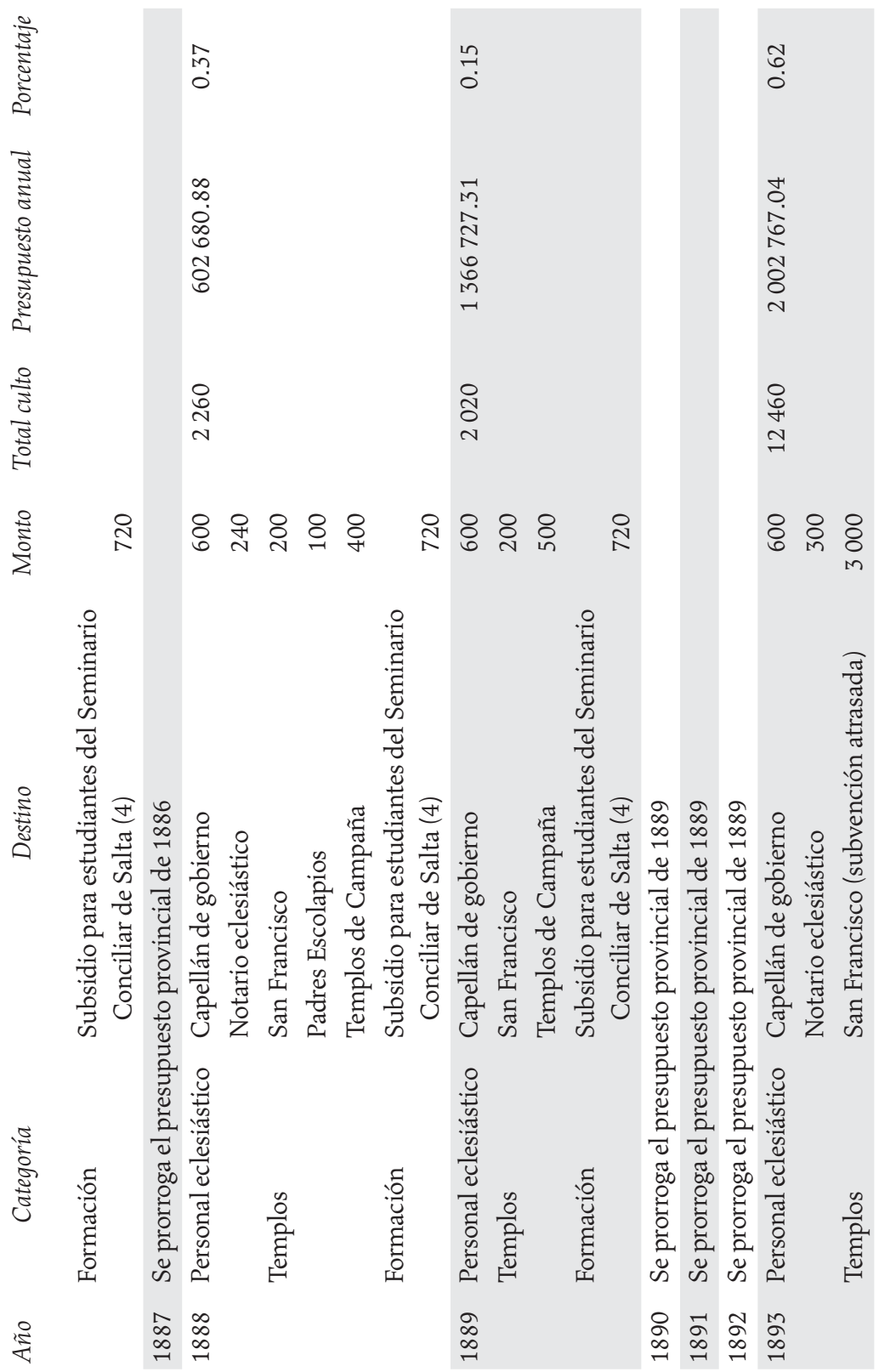


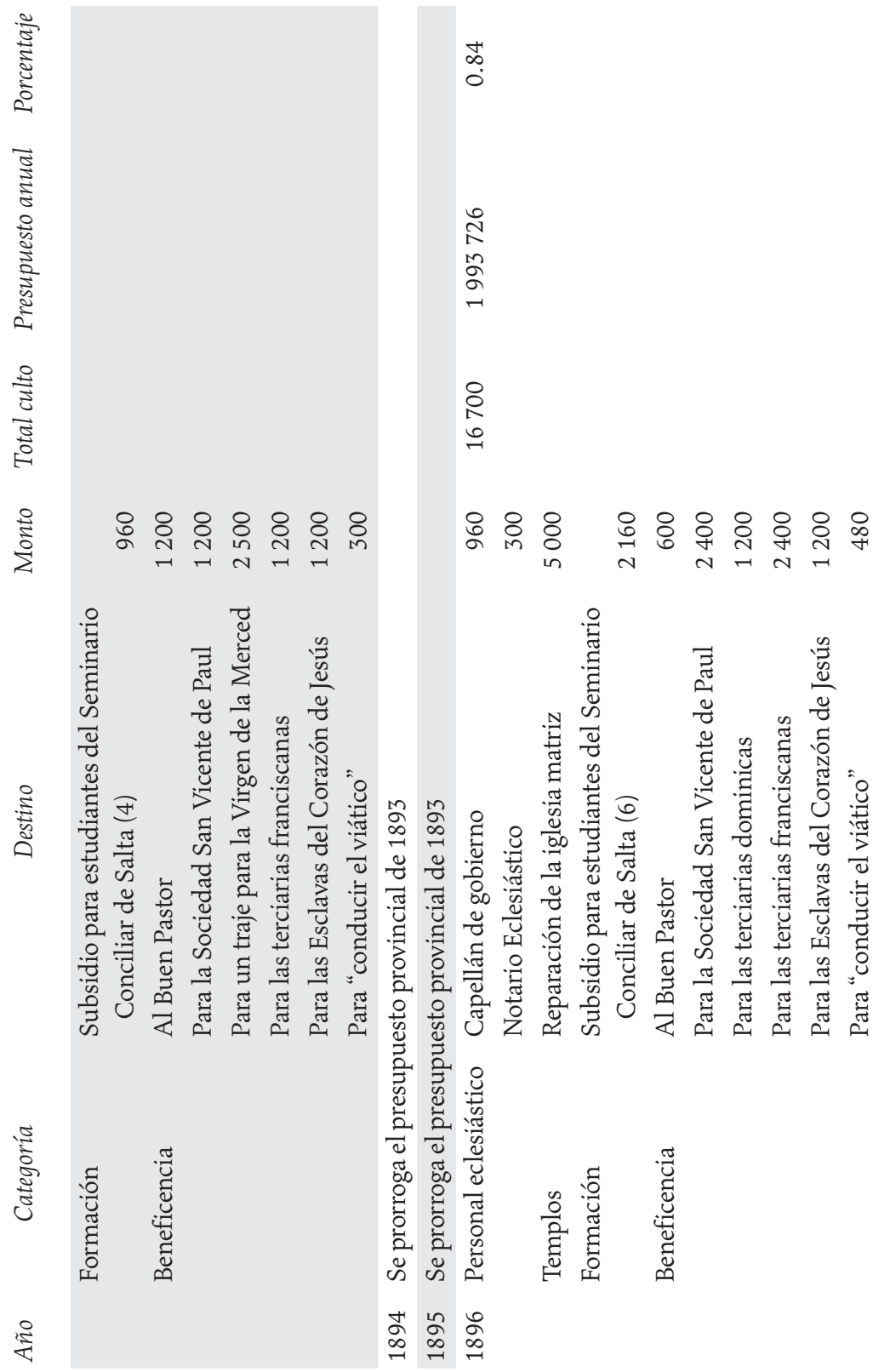




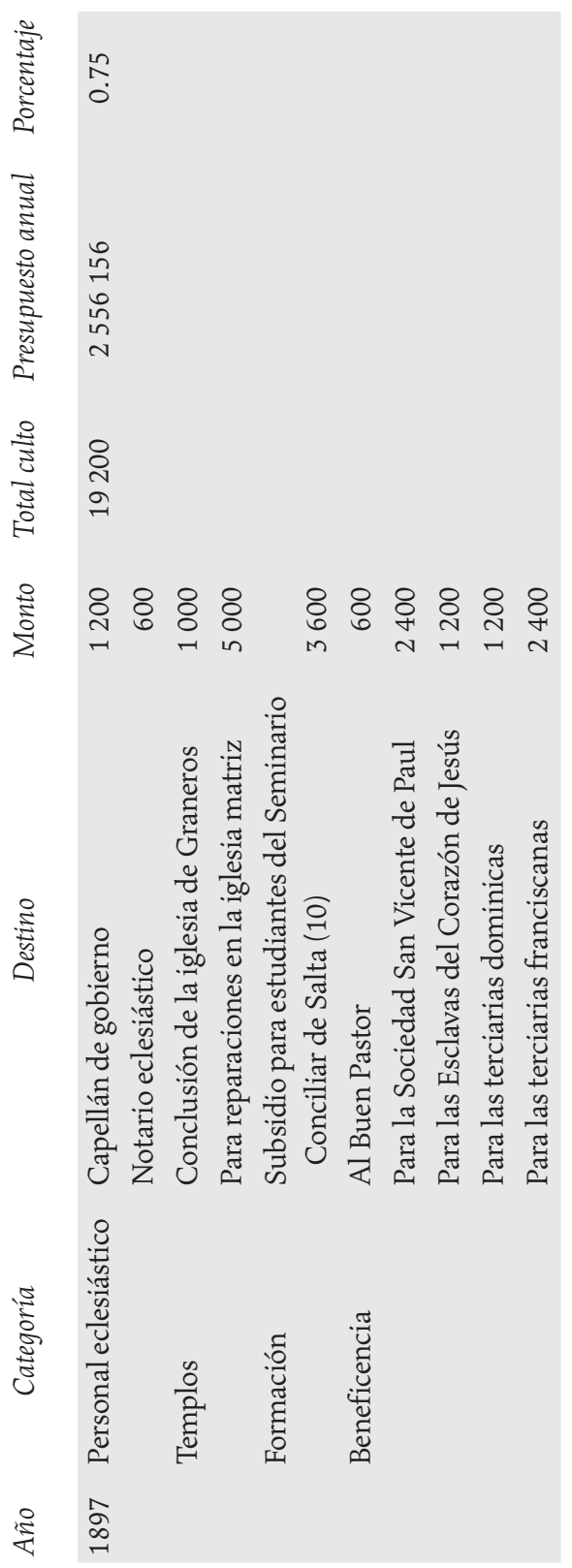

空

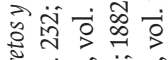

is

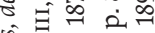

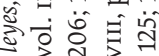

है से 2 -

E $\rightarrow$ i

홍 क्ष

政宛

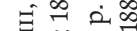

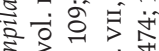

के

$\approx$ z

वै 手

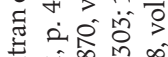

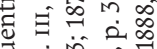

牙

वे

象

Fअं

पै के

至

क्षे

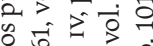

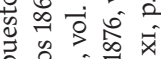

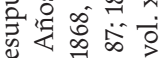

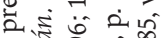

क है के $5 \stackrel{\infty}{\circ}$

ष हैं

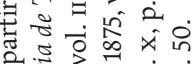

a

to 000

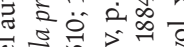

ष

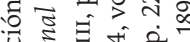

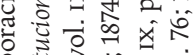

क

$\because$ है

䒕 형

解

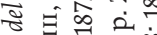

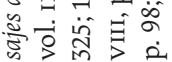




\section{LISTA DE REFERENCIAS}

Ábalo, E. (2013a). Dinámicas involucradas en el nombramiento de eclesiásticos en la vicaría foránea de Tucumán durante la segunda mitad del siglo XIX. Itinerantes. Revista de Historia y Religión, 3, 103-132. Recuperado de http://revistas.unsta.edu. ar/index.php/Itinerantes/article/view/75

Ábalo, E. (2013b). Las asignaciones para el culto en el presupuesto de la provincia de Tucumán, Argentina (1852-1897). Boletín Americanista, LXIII(66), 121-142. Recuperado de https:/www.raco.cat/index.php/BoletinAmericanista/article/view $/ 271823 / 359655$

Ábalo, E. (2014). La construcción de templos en el sur de la provincia de Tucumán durante la segunda mitad del siglo xIx. En S. Amenta (coord.), Aportes para la historia de la diócesis de la Santísima Concepción (pp. 67-83). Tucumán: UnstA.

Barral, M. E. (2010). Un salvavidas de plomo. Los curas rurales de Buenos Aires y la reforma eclesiástica de 1822. Prohistoria, XIV(14), 11-27. Recuperado de https:// www.redalyc.org/pdf/3801/380135842001.pdf

Barral, M. E. y Binetti, J (2014). Sostener el culto. Estado, clero y religiosidad en Buenos Aires, 1822-1852. Itinerantes. Revista de Historia y Religión, 4, 41-70. Recuperado de http://revistas.unsta.edu.ar/index.php/Itinerantes/article/view/58

Bravo, M. C. (2008). Campesinos, azúcar y política: cañeros, acción corporativa y vida política en Tucumán (1895-1930). Rosario: Prohistoria Ediciones.

Bruno, C. (1975). Historia de la Iglesia en la Argentina (vol. x). Buenos Aires: Don Bosco.

Calvo, N. (2001). "Cuando se trata de la civilización del clero". Principios y motivaciones del debate sobre la reforma eclesiástica porteña de 1822. Boletín del Instituto de Historia Argentina y Americana Dr. Emilio Ravignani, 24, segundo semestre, 73-103.

Campi, D. (2000). Economía y sociedad en las provincias del norte. En M. Z. Lobato (dir.), El progreso, la modernización y sus límites (1880-1916) (t. v, pp. 71-116). Buenos Aires: Sudamericana (Colección Nueva Historia Argentina).

Comas, M. F. (2013). Las moradas de Dios en los pueblos de Buenos Aires. Vecinos y autoridades frente al patronato (1852-1854). En M. Canedo (comp.), Poderes intermedios en la frontera: Buenos Aires, siglos XVIII-XIX (pp. 121-144). Mar del Plata: EUDEM.

Cordeiro, R. y Viale, C. D. (comps.) (1915-1919). Compilación ordenada de leyes, decretos y mensajes del periodo constitucional de la provincia de Tucumán que comienza en el año 1852 (vols. I-VII). Tucumán: Edición Oficial.

Di Stefano, R. (2004). El púlpito y la plaza. Clero, sociedad y política de la monarquía católica a la república rosista. Buenos Aires: Siglo XXI. 
Di Stefano, R. (2008). Ut unum sint. La reforma como construcción de la Iglesia (Buenos Aires, 1822-1824), Rivista di Storia del Cristianesimo, 3, 499-523. Recuperado de https://www.academia.edu/3658684/_Ut_unum_sint._La_reforma_como_cons trucci\%C3\%B3n_de_la_Iglesia_Buenos_Aires_1822-1824_Rivista_di_Storia_del _Cristianesimo_No_3_2008_p\%C3\%A1gs._499-523

Di Stefano, R. (2010). En torno del presupuesto de culto y sus raíces históricas. Criterio, 2366. Recuperadodehttp://www.revistacriterio.com.ar/bloginst_new/2010/12/06/ en-torno-del-presupuesto-de-culto-y-sus-raices-historicas/

Di Stefano, R. (2013a). Sobre liberalismo y religión: rentas eclesiásticas y presupuesto de culto en el Estado de Buenos Aires (1852-1862). Almanack, 5, 178-197. Recuperado de http://www.almanack.unifesp.br/index.php/almanack/\%20article/view/982

Di Stefano, R. (2013b). Lay patronage and the development of ecclesiastical property in Spanish America: The case of Buenos Aires, 1700-1900. Hispanic American Historical Review, 93(1), 67-98. DoI: https://doi.org/10.1215/00182168-1902715

Di Stefano, R. y Zanatta, L. (2000). Historia de la Iglesia argentina. Desde la conquista hasta fines del siglo xx. Buenos Aires, Grijalbo Mondadori.

Di Stefano, R. y Zanatta, L. (2009). Historia de la Iglesia argentina. Desde la conquista hasta fines del siglo Xx. Buenos Aires: Sudamericana.

Echeverría, E. (2003). El dogma socialista a la juventud argentina [1837]. Biblioteca Virtual Universal. Recuperado de: http://www.biblioteca.org.ar/libros/1238.pdf

Folquer, C. (2012). Viajeras hacia el fondo del alma. Sociabilidad, política y religiosidad en las Dominicas de Tucumán, Argentina, 1886-1911 (Tesis inédita de doctorado). Universidad de Barcelona.

Frizzi de Longoni, H. (1947). Rivadavia y la reforma eclesiástica. Buenos Aires: La Prensa Médica Argentina.

Gallardo, G. (1962). La política religiosa de Rivadavia. Buenos Aires: Ediciones Theoría.

Garavaglia, J. C. (2013). La construcción nacional en la Argentina. Rentas, presupuestos y niveles de estatalidad (1856-1865). Prohistoria, XVI(20), 3-43. Recuperado de https://www.redalyc.org/pdf/3801/380134161001.pdf

Gregorio de Tejada, M. T. (1993). Vocabulario básico de historia de la Iglesia. Barcelona: Crítica.

Guy, D. (2008). Política azucarera argentina. Tucumán y la generación del ochenta. Tucumán: EDUNT.

Herrera, C. (2010). Fiscalidad y poder: las relaciones entre el estado tucumano y el Estado central en la formación del sistema político nacional, 1852-1869. En B. Bragoni y E. Míguez (coords.). Un nuevo orden político. Provincias y Estado Nacional, 1852-1880. Buenos Aires: Biblos. 
Lanteri, A. L. (2011). Las provincias en un ámbito de poder institucionalizado. El Congreso de Paraná en la Confederación, 1854-1861. Estudios Sociales, 41(1), 69-95. DOI: https://doi.org/10.14409/es.v41i1.2682

Levaggi, A. (1994). Notas sobre el tratamiento de la religión católica por el derecho argentino (1853-1900). Archivum, xVI, 205-220.

Lida, M. (2007a). El presupuesto de culto en la Argentina y sus debates. Estado y sociedad ante el proceso de construcción de la Iglesia (1853-1880). Andes, 18. Recuperado de http://www.scielo.org.ar/scielo.php?script=sci_arttext\& pid=S1668-80902007000100002

Lida, M. (2007b). La Iglesia católica en las más recientes historiografías de México y Argentina. Religión, modernidad y secularización. Historia Mexicana, 56(4), 13931426. Recuperado de https://historiamexicana.colmex.mx/index.php/RHM/ article/view/1640/1458

Martínez, I. (2013). Una nación para la Iglesia argentina. Construcción del Estado y jurisdicciones eclesiásticas en el siglo XIX. Buenos Aires: Academia Nacional de la Historia.

Martínez, I. (2015). Nuevos espacios para la construcción de la Iglesia: Estado nacional y sectores ultramontanos en la Confederación Argentina, 18531862. Quinto Sol, 19(3), 1-23. Recuperado de http://www.scielo.org.ar/scielo. php?script=sci_arttext\&pid=S1851-28792015000300002\&lng=es\&tlng=es

Mauro, D. y Martínez, I. (2015). Secularización, Iglesia y política en Argentina. Balance teórico y síntesis histórica. Rosario: FHUMyar Ediciones.

Meyer, L. (2008). La catedral y el cabildo de San Miguel de Tucumán. Tucumán: Centro Cultural Alberto Rougués.

Molina, S. M. (1994). Contribución al estudio de la industria azucarera en Tucumán. En S. M. Molina y E. Muñoz Moraleda (coords.), Temas del Tucumán (pp. 277-295). Tucumán: Secretaría de Posgrado de la Universidad Nacional de Tucumán.

Navarro Floria, J. G. (2011). Sobre el presupuesto de culto. Criterio Digital, 2368. Recuperado de https://www.revistacriterio.com.ar/bloginst_new/2011/03/01/sobre-elpresupuesto-de-culto/

Páez de la Torre, C., hijo (1987). Historia de Tucumán. Buenos Aires: Plus Ultra.

Peire, J. y Di Stefano, R. (2004). De la sociedad barroca a la ilustrada: aspectos económicos del proceso de secularización en el Río de la Plata. Andes, 15, 117-150.

Piccirilli, R. (1943). Rivadavia y su tiempo. Buenos Aires: Peuser.

Rex Bliss, S. (2004). La fiscalidad provincial entre la Constitución y el despegue azucarero. Tucumán, 1852-1876. En L. Bonano (coord.), Estudios de historia social de Tucumán. Educación y política en los siglos XIX y Xx (pp. 11-41). Tucumán: Facultad de Filosofía y Letras-UnT. 
Rottjër, A. (1958). El presupuesto de culto en Argentina. Buenos Aires: Comisión de Documentación y Publicidad del Episcopado.

Sánchez Loria, H. y Moral, E. M. del (comps.) (1915-1919). Compilación ordenada de leyes, decretos y mensajes del período constitucional de la provincia de Tucumán que comienza en el año 1852 (vols. VIII-XXIV). Tucumán: Edición Oficial.

Sánchez Román, J. A. (2005). La dulce crisis: Estado, empresarios e industria azucarera en Tucumán, Argentina (1853-1914). Sevilla: Secretariado de Publicaciones de la Universidad de Sevilla.

Udaondo, E. (1957) Antecedentes del presupuesto de culto en la República Argentina. [primera edición 1949]. Buenos Aires: s. e. 